\title{
Article
}

\section{Heparan sulfate disaccharide measurement from biological samples using precolumn derivatization, UPLC-MS and single ion monitoring}

Antia, Imeobong, Yagnik, Darshna, Pantoja Munoz, Leonardo, Shah, Ajit and Hills, Frank

Available at http://clok.uclan.ac.uk/38202/

Antia, Imeobong ORCID: 0000-0001-6620-1903, Yagnik, Darshna, Pantoja Munoz, Leonardo, Shah, Ajit and Hills, Frank (2017) Heparan sulfate disaccharide measurement from biological samples using precolumn derivatization, UPLC-MS and single ion monitoring. Analytical Biochemistry, 530 . pp. 17-30. ISSN 0003-2697

It is advisable to refer to the publisher's version if you intend to cite from the work. http://dx.doi.org/10.1016/j.ab.2017.04.019.

For more information about UCLan's research in this area go to http://www.uclan.ac.uk/researchgroups/ and search for <name of research Group>.

For information about Research generally at UCLan please go to http://www.uclan.ac.uk/research/

All outputs in CLoK are protected by Intellectual Property Rights law, including Copyright law. Copyright, IPR and Moral Rights for the works on this site are retained by the individual authors and/or other copyright owners. Terms and conditions for use of this material are defined in the policies page. 


\section{Accepted Manuscript}

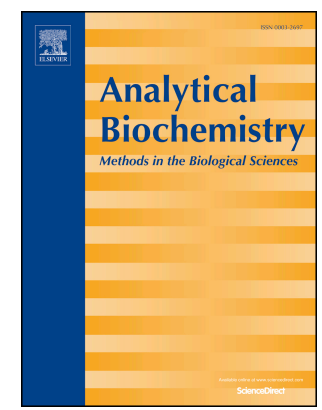

Heparan sulfate disaccharide measurement from biological samples using precolumn derivatization, UPLC-MS and single ion monitoring

Imeobong U. Antia, MSc, Darshna R. Yagnik, Ph.D, Leonardo M. Pantoja, Ph.D, Ajit J. Shah, Ph.D, Frank A. Hills, Ph.D

PII: S0003-2697(17)30187-2

DOI: 10.1016/j.ab.2017.04.019

Reference: YABIO 12686

To appear in: Analytical Biochemistry

Received Date: 24 January 2017

Revised Date: 6 March 2017

Accepted Date: 27 April 2017

Please cite this article as: I.U. Antia, D.R. Yagnik, L.M. Pantoja, A.J. Shah, F.A. Hills, Heparan sulfate disaccharide measurement from biological samples using pre-column derivatization, UPLC-MS and single ion monitoring, Analytical Biochemistry (2017), doi: 10.1016/j.ab.2017.04.019.

This is a PDF file of an unedited manuscript that has been accepted for publication. As a service to our customers we are providing this early version of the manuscript. The manuscript will undergo copyediting, typesetting, and review of the resulting proof before it is published in its final form. Please note that during the production process errors may be discovered which could affect the content, and all legal disclaimers that apply to the journal pertain. 


\section{Title}

Heparan sulfate disaccharide measurement from biological samples using pre-column derivatisation, UPLC-MS and single ion monitoring

\section{Author names and Affiliations}

Imeobong U Antia, MSc ${ }^{\text {a }}$; Darshna R Yagnik, Ph.Da; Leonardo M Pantoja, PhD Ajit J Shah, Ph. D and Frank A Hills, Ph.D ${ }^{a}$

aGlycan Research Group, Department of Natural Sciences, Faculty of Science and Technology, Middlesex University, The Burroughs, London NW4 4BT, UK

email addresses:

Imeobong U Antia i.antia@mdx.ac.uk

Darshna R Yagnik d.yagnik@mdx.ac.uk

Leonardo M Pantoja L.PantojaMunoz@mdx.ac.uk
Ajit J Shah
a.j.shah@mdx.ac.uk
Frank A Hills
f.hills@mdx.ac.uk

\section{Corresponding Author details:}

Dr Frank A Hills

Glycan Research Group, Department of Natural Sciences, Faculty of Science and Technology, Middlesex University, The Burroughs, London NW4 4BT, UK Tel: (+44) 2084115726 email: f.hills@mdx.ac.uk

Keywords: Heparan sulphate; cancer cell lines; Glycosaminoglycan; Proteoglycan; 2aminoacridone; RP-UPLC-MS 


\subsection{Introduction}

Glyosaminoglycans (GAGs) are long unbranched polysaccharide chains composed of repeating disaccharide subunits of alternating uronic acid and glycosamine (GlcN) residues. These molecules have a large net negative charge as a result of a complex arrangement of $\mathrm{N}$ - and/or O-linked sulfate binding on the sugar moieties. Heparin is the best known GAG and is expressed exclusively by mast cells [1], Other GAGs include heparan sulfate (HS), chondroitin sulfate (CS), dermatan sulfate (DS) and keratan sulfate (KS). These are ubiquitously expressed on the extracellular matrix and bound, via serine residues, to protein cores on many cell surfaces in the form of proteoglycans (PGs) [2].

Whilst heparin is well known for its anticoagulant properties, there is increasing evidence that heparin and other GAGs can influence cell functions through a diverse range of activities that include the regulation of cell survival, growth, differentiation and angiogenesis and invasion $[3,4,5]$. Although the molecular mechanism of the action of GAGs is not well understood, accumulating evidence suggests that the effects of heparan sulfate glycosaminoglycans may be attributable at least in part to their binding of the growth factors and regulating of their signaling $[6,7]$.

GAGs show considerable variation in chain length and degree of sulfation on either sugar in the disaccharide subunit. In the case of HS, the disaccharide units are differentially sulfated on the C-6 carbon or N position of the GlcN, on C-2, or occasionally on C-3, of the GlcA/ldoA subunit [8]. The polysaccharide chain length coupled with the variation in the extent of sulfation, give rise to hundreds of potential polysaccharide structural combinations.

GAGs have been implicated in a wide variety of pathology including respiratory failure [9], placental malaria [10] and cancer [11]. HS and CS have been shown to be important for the initial attachment of Merkel cell polyomavirus (MCV) to cells while 6-O-sulfated and $\mathrm{N}$ sulfated HS is important for the reporter vector entry [12] Determining the composition of these GAGs is important in understanding their role. Depolymerization of GAGs and analysis of their disaccharides is an important step in the characterization of GAGs. Depolymerization can be achieved using specific lyases which cleave the glycosidic linkage between a hexosamine and a hexuronic acid thus introducing an unsaturated bond (absorbing at 232 $\mathrm{nm}$ ) between the C4 and C5 of the hexuronic acid. GAGs can also be depolymerized chemically by mild hydrazinolysis and subsequent deaminative cleavage with nitrous acid [13]. This method retains the original epimeric nature of the hexuronic acid but loses information about the $\mathrm{N}$-sulfation or $\mathrm{N}$-acetylation because the resulting disaccharide comprise a hexuronic acid linked to a 2,5-anhydrohexose bearing an aldehyde group [13].

Enzymatic depolymerization of heparin/heparan sulfate (hep/HS) with heparinises give rise to twelve disaccharides out of which only eight are commonly seen in normal organisms [14, 
15]. The other four ( $\mathrm{N}$-unsubstituted glucosamine) are rare and are believed to result from the loss of labile $\mathrm{N}$-sulfate groups during isolation or incomplete modification ( $\mathrm{N}$ deactylase/N-sulfotransferase) during hep/HS biosynthesis [14]. These twelve hep/HS disaccharides are commercially available.

Previous techniques used for the compositional analysis of GAG disaccharides include liquid chromatography (LC) with UV [16], fluorescence [17], and MS detection. These GAG disaccharides are hydrophilic and hence will not be well retained on a reverse phase (RP) column. Underivatized GAG disaccharides can be analyzed directly using a variety of separation methods including hydrophilic interaction liquid chromatography (HILIC)-MS. However, co-elution of disaccharides has been reported [13]. To overcome these issues, GAG disaccharides may be derivatized with a hydrophobic fluorophore which increases their retention on RPLC and may improve MS sensitivity. Derivatizing reagents employed for this include 4,4-difluoro-5,7-dimethyl-4-bora-3a-diaza-s-indacene-3-propionic acid (BODIPY) and 2-aminobenzamide [14]. Retention of GAG disaccharides and oligosaccharides may also be improved using ion pair RPLC with reagents such as tetrabutylammonium [18], n-hexylamine, and n-pentylamine. [19] However, each of these has specific additional drawbacks that make analysis of GAG disaccharides problematic, particularly when analyzing biological samples. These require long run times and some of the non-volatile ion pairing reagents contaminate the MS interface [20]. Capillary electrophoresis with laser-induced fluorescent detection [21] and fluorophore-assisted carbohydrate electrophoresis (FACE) [22] have also been employed in GAG disaccharide analysis. However, both of these methods could suffer from poor reproducibility of migration times.

There is therefore a need to develop a more rapid, selective and sensitive method to quantify levels of GAG disaccharides in biological samples. In this article, we report a method of rapid separation and detection of twelve heparin/heparan sulfate disaccharides and an internal standard in $11 \mathrm{~min}$. This method demonstrates excellent reproducibility, which does not require the specialized separation techniques needed for the separation of native disaccharides and has been successfully applied to the comparison of disaccharide expression in a variety of human cancer cell lines. Derivization-based methods frequently report the use of highly toxic reducing agents such cyanoborohydride. The method described uses the less toxic 2-methylpyridine borane. This analysis employs an optimized selected ion recording (SIR) precolumn RP-UPLC-MS method based on 2-aminoacridone derivatization without the need to remove excess unreacted reagent. We have applied this method to the analysis of disaccharide levels in a variety of human cell lines. 


\subsection{Materials and methods}

\subsection{Materials}

Actinase (from Streptomyces griseus), 2-aminoacridone (AMAC), 2-methylpyridine borane complex, heparan sulfate (sodium salt from bovine kidney), anion exchange spin columns, 3 $\mathrm{kDa}$, and $10 \mathrm{kDa}$ molecular weight cut off filters were purchased from Sigma-Aldrich, (Poole, UK). Twelve unsaturated heparin/HS disaccharides ( $\triangle U A, 2 S$ - GlcNS,6S; $\triangle U A, 2 S-G l c N S$; $\triangle U A, 2 S$ - GlcNAc,6S; $\triangle U A-G l c N S, 6 S ; \Delta U A-G l c N S ; \Delta U A-G l c N A c ; \triangle U A, 2 S-$ GlcNAc; $\triangle U A-$ GlcNAc,6S; $\triangle \mathrm{UA}, 2 \mathrm{~S}$ - GlcN; $\triangle \mathrm{UA}, 2 \mathrm{~S}-\mathrm{GlcN}, 6 \mathrm{~S} ; \Delta \mathrm{UA}-\mathrm{GlcN}, 6 \mathrm{~S} ; \Delta \mathrm{UA}-\mathrm{GlcN})$ and an internal standard ( $\triangle \mathrm{UA}, 2 \mathrm{~S}$ - GlcNCOEt,6S) were purchased from Iduron (Manchester, UK). Heparinases (from Flavobacterium heparinum) I, II, and III were also purchased from Iduron (Manchester, UK). Acetic acid, LC-MS grade dimethyl sulfoxide (DMSO), LC grade ammonium acetate, methanol, and UPLC water were purchased from Fisher Scientific, (Loughborough, UK).

\section{$2.2 \quad$ Cell culture}

GAGs were extracted from a variety of human cell lines grown in our laboratory. These included cell lines from ovarian adenocarcinoma (OVCAR-3), metastatic breast adenocarcinoma (MDA-468), acute myeloid leukaemia (MOLM-13), choriocarcinoma (BeWo) and a colon cancer cell line (HCT116). Cells were incubated at $37^{\circ} \mathrm{C}$ in media containing $10 \%$ fetal bovine serum , $1 \%$ penicillin and streptomycin (Thermofisher, Hemel Hempsted, UK) in an atmosphere containing $5 \% \mathrm{CO}_{2}$. All cells were cultured using RPMI 1640 medium except HCT116 cells which were cultured using DMEM (Sigma) and BeWo cells were cultured using DMEM:F12. All cell lines were purchased from LGC standards (Teddington, UK) with the exception of MOLM-13 cells (DSMZ, Braunschweig, Germany) and were cultured for at least two passages prior to GAG analysis.

\subsection{Extraction and enzymatic depolymerization of heparin/HS disaccharides from cells}

We used an adaptation of the extraction method reported by Han, et al. [23] and Volpi, et al. [24] for the extraction of heparin/HS from cells. Briefly, cells grown to confluence were scraped gently from the flask and washed in $100 \mathrm{mM}$ phosphate buffered saline. They were then incubated with actinase $(20 \mathrm{mg} / \mathrm{mL})$ for $18 \mathrm{~h}$ to proteolyse intracellular and membrane 
bound proteins. The resulting solution was filtered to remove particulates, and the peptides removed using a $10 \mathrm{kDa}$ molecular weight cut-off filter. The retenate was lyophilized and resuspended in $8 \mathrm{M}$ urea with $2 \%$ CHAPS. Anion exchange spin columns were used to extract GAGs from this mixture, washed with $200 \mathrm{mM} \mathrm{NaCl}$ and subsequently eluted with $16 \% \mathrm{NaCl}$. This solution was desalted using a $3 \mathrm{kDa}$ molecular weight cut-off filter, lyophilized, and resuspended in $50 \mathrm{mM}$ phosphate buffer ( $\mathrm{pH}$ 7.0). Time-controlled enzymatic depolymerization of the GAGs was achieved by the addition of $3 \mathrm{mIU}$ of heparinase I, II, and III at $37^{\circ} \mathrm{C}$ for 48 $\mathrm{h}$ as described above. The solution was then heated in boiling water for $10 \mathrm{~min}$ and centrifuged at $12,000 \times \mathrm{g}$ for $10 \mathrm{~min}$ to remove denatured proteins. The supernatant was collected and $0.5 \mu \mathrm{L}$ of internal standard ( $\triangle \mathrm{UA}, 2 \mathrm{~S}$ - GlcNCOEt,6S, $1 \mathrm{mg} / \mathrm{mL}$ ) was added. This was then lyophilized, derivatized with AMAC and analyzed using UPLC-MS.

In order to determine the recovery of disasccharides from this extraction procedure, heparan sulfate standards (5 and $10 \mu \mathrm{g}$ ) were extracted and disaccharides quantified as descibed above (extracted HS). In addition, the same amount of HS was directly digested with heparinases without prior extraction and then further processed as above (unextracted HS). For each HS subunit the recovery was determined as the amount detected from extracted $\mathrm{HS}$ as a percentage from that obtained from unextracted $\mathrm{HS}$.

\subsection{Derivatization of heparin/HS disaccharide standards}

The heparin/HS disaccharides were derivatized pre-column using AMAC employing a modification of the method reported by Volpi, et al. [24]. Briefly, solutions containing heparin/HS disaccharides were lyophilized and re-dissolved in a solution of $0.1 \mathrm{M} \mathrm{AMAC}$ in a mixture of DMSO and acetic acid $(17: 3, \mathrm{v} / \mathrm{v})$. The mixture was then incubated at room temperature for $15 \mathrm{~min}$ and then an equal volume of 2-methylpyridine borane complex $(1 \mathrm{M})$ in acetonitrile was added. This mixture was centrifuged at $10,000 \times \mathrm{g}$ for $1 \mathrm{~min}$ at room temperature and incubated at $45{ }^{\circ} \mathrm{C}$ for $4 \mathrm{~h}$. Prior to injection the sample volume was adjusted to $200 \mu \mathrm{L}$ with a mixture of DMSO : water $(1: 1, \mathrm{v} / \mathrm{v})$.

\subsection{Optimization of AMAC derivatization of heparin/HS disaccharides}

To determine the optimal concentration of AMAC, 12 heparin/HS disaccharides and the internal standard $(0.5 \mu \mathrm{g}$ each) were incubated with different concentrations of AMAC over a range of $0.53-4.20 \mathrm{mg} / \mathrm{mL}$ using the procedure described in Section 2.4. In order to determine the optimum temperature for derivatization, the optimal AMAC concentration $(2.1$ 
$\mathrm{mg} / \mathrm{mL}$ ) was used to derivatize a mixture of 12 heparin/HS disaccharides containing $0.5 \mu \mathrm{g}$ of each disaccharide as described above. The samples were then incubated at 37,45 , or 65 ${ }^{\circ} \mathrm{C}$ for $4 \mathrm{~h}$ and subsequently analyzed. To optimize incubation time a mixture of 12 heparin/HS disaccharides was derivatized under optimal conditions of AMAC concentration and incubation temperature for $2,4,6$, and $8 \mathrm{~h}$ and subsequently analyzed as described above.

\subsection{Optimization of UPLC-MS conditions}

Individual heparin/HS disaccharides were derivatized using optimized conditions described in Section 2.5 and analyzed using UPLC-MS as described above. A mixture of 12 AMACderivatized heparin/HS disaccharides was injected at a concentration of $1 \mu \mathrm{g} / \mathrm{mL}$ for the optimization of desolvation temperature, cone and extractor voltages. MS detection was based on the most intense ions observed from trisulfated and disulfated disaccharides while single ions were seen for the mono and non-sulfated disaccharides. Desolvation temperature, cone voltage and extractor voltage were varied between $300-400{ }^{\circ} \mathrm{C},-15-75 \mathrm{~V}$ and $-1-4$ $\mathrm{V}$ respectively. For all further experiments, the optimized conditions for AMAC concentration, incubation conditions, desolvation temperature, and extractor voltage were $2.1 \mathrm{mg} / \mathrm{mL}, 4 \mathrm{~h}$, $45^{\circ} \mathrm{C}$ for $4 \mathrm{~h}, 350{ }^{\circ} \mathrm{C}$ and $3 \mathrm{~V}$ respectively. Individual cone voltages were used for each of the derivatized disaccharides.

\section{$2.7 \quad$ UPLC-MS conditions}

A Waters Acquity H-Class UPLC system with an SQ Detector 2 was used for the LC-MS analysis. Separation was performed using an ACQUITY BEH Shield RP 18 column (1.7 $\mu \mathrm{m}$, $2.1 \times 150 \mathrm{~mm}$; Waters, Ireland, UK) maintained at $45^{\circ} \mathrm{C}$. Separation was achieved using gradient elution. Solvent $A$ and $B$ were $80 \mathrm{mM}$ ammonium acetate and methanol respectively and were delivered at a flow rate of $0.3 \mathrm{~mL} / \mathrm{min}$. The gradient was as follows; Solvent $A$ and $12 \%$ B for 1.7 min followed by a linear gradient of $12-15 \%$ B from $1.7-5 \mathrm{~min}, 15-30 \% \mathrm{~B}$ from 5 - $10 \mathrm{~min}, 30$ - $100 \%$ B from $10-10.7,100 \%$ B from $10.7-13.3$ mins, $100-12 \%$ B from $13.3-13.7$ mins and $12 \%$ B from 13.7 - 18 mins. An aliquot $(5 \mu \mathrm{L})$ of each sample was injected onto the column.

Eluates were detected using a single quadrupole mass spectrometer equipped with an ESI source operated in negative ion mode. The capillary voltage was set to $-3 \mathrm{kV}$; source temperature, $150{ }^{\circ} \mathrm{C}$; source gas flow, $800 \mathrm{~L} / \mathrm{hr}$ and cone gas flow $50 \mathrm{~L} / \mathrm{hr}$. The MS probe position was optimized to $4 \mathrm{~mm}$ vertical and $5.1 \mathrm{~mm}$ horizontal for the detection of AMAC- 
derivatized heparin/HS disaccharides. Data was acquired using selected ion recording (SIR) and was analyzed using the MassLynx ${ }^{\circledR}$ software version 4.1 .

\subsection{Linearity, Limits of detection, quantification and reproducibility}

A mixture of 12 Heparin/HS disaccharides and an internal standard ( $\triangle \mathrm{UA}, 2 \mathrm{~S}$ GlcNCOEt,6S) were derivatized and analyzed in duplicate using optimum conditions at a range of concentrations $(0.019-10 \mu \mathrm{g} / \mathrm{mL})$ of each disaccharide. Simple least squares regression analysis was used to determine linearity. The limits of detection and quantification were the lowest concentration that produced a signal:noise ratio of at least 3:1 and 10:1 respectively. Reproducibility was determined at concentrations of $0.625,1.25$, and $5 \mu \mathrm{g} / \mathrm{mL}$ and was defined as the coefficient of variation from five consecutive injections. 


\subsection{Results and discussion}

Prior to derivatization studies, we conducted extensive studies to determine the optimum conditions for efficient separation of disaccharide subunits using HPLC. We found that effective separation of all thirteen disaccharides could be achieved in $11 \mathrm{~min}$. With additional column reconditioning prior to analysis of the next sample, this gives a total run time of 18 $\min$.

\subsection{Optimization of Derivatization conditions}

Figure 1a shows the effect of AMAC concentration on ion intensity (LC-peak area). We found that the optimum concentration was $2.1 \mathrm{mg} / \mathrm{mL}$. This concentration achieved the highest LCpeak area for all except two of the disaccharides ( $\triangle U A-$ GIcN and $\Delta U A, 2 S-$ GlcNS). This concentration was used for all subsequent experiments. Interestingly, lower LC-peak areas were observed at higher AMAC concentrations. This may be attributed to signal suppression due to excess unreacted AMAC. It was also observed that the same concentration of different disaccharides produced significantly different LC-peak areas. It seems likely that this is due to differences in their efficiencies of ionization with $\triangle U A, 2 S-$ GIcNAc and $\triangle U A, 2 S$ - GlcNS,6S producing the highest and lowest LC-peak areas respectively with a ten-fold difference between them.

The optimum temperature for derivatization was found to be $45^{\circ} \mathrm{C}$. Above this temperature a reduction in signal intensity was observed with all disaccharides except for $\triangle U A$ - GlcN, $\Delta U A$ -GlcN,6S, $\Delta \mathrm{UA}, 2 \mathrm{~S}-\mathrm{GlcN}$ and $\Delta \mathrm{UA}, 2 \mathrm{~S}-\mathrm{GlcN}, 6 \mathrm{~S}$ (Fig 1b). Subsequent analysis revealed that this reduction in signal intensity of the $\mathrm{N}$-substituted disaccharides at higher temperatures was due to the loss of sulfonic groups during derivatization resulting in the formation of $\mathrm{N}$ unsubstituted HS disaccharide forms. Thus, $\Delta \mathrm{UA}, 2 \mathrm{~S}-\mathrm{GlcNS}, 6 \mathrm{~S} \rightarrow \Delta \mathrm{UA}, 2 \mathrm{~S}-\mathrm{GlcN}, 6 \mathrm{~S}$, $\Delta \mathrm{UA}, 2 \mathrm{~S}-\mathrm{GlcNS} \rightarrow \Delta \mathrm{UA}, 2 \mathrm{~S}-\mathrm{GlcN}, \Delta \mathrm{UA}-\mathrm{GlcNS}, 6 \mathrm{~S} \rightarrow \Delta \mathrm{UA}-\mathrm{GlcN}, 6 \mathrm{~S}$, and $\Delta \mathrm{UA}-\mathrm{GlcNS} \rightarrow \Delta \mathrm{UA}-$ GlcN. Some loss of these sulfonic groups was observed at $45^{\circ} \mathrm{C}$. Previous studies have noted that GAG N-sulfate groups are labile and may be lost during dervatization [14]. This breakdown is demonstrated using $\triangle \mathrm{UA}, 2 \mathrm{~S}-\mathrm{GlcNS}, 6 \mathrm{~S}$ as an example (Figure 1c). At $45^{\circ} \mathrm{C}$, $\triangle \mathrm{UA}, 2 \mathrm{~S}-\mathrm{Gl} \mathrm{cN}, 6 \mathrm{~S}$ was formed during derivatization. When the temperature was increased to $65^{\circ} \mathrm{C}$, three N-unsubstituted ( $\Delta \mathrm{UA}, 2 \mathrm{~S}-\mathrm{GlcN}, 6 \mathrm{~S}, \Delta \mathrm{UA}-\mathrm{GlcN}, 6 \mathrm{~S}$, and $\Delta \mathrm{UA}, 2 \mathrm{~S}-\mathrm{GlcN}$ ) and one $\mathrm{N}$-substituted HS disaccharide ( $\triangle \mathrm{UA}$-GlcNS) were formed. We did not see any loss of sulfo groups from N-unsubstituted disaccharides during derivatization. 
The reduction in the MS signal for the non-sulfated N-substituted disaccharide ( $\triangle U A-G \mid c N A c)$ may be due to the breakage of the glycosidic bond linking Glc and GlcNAc with increasing derivatization temperature. The resulting non-sulfated GICNAC-AMAC residue would only be minimally ionized in the ESI negative ion mode employed in this work.

For all subsequent experiments, an incubation temperature of $45{ }^{\circ} \mathrm{C}$ was used for derivatization in order to optimize the signal intensity and minimize the loss of sulfonic groups. Figure 1d shows single ion recording chromatograms of $\triangle \mathrm{UA}-$ GlcNS at three different incubation temperatures. It was noted that the LC-peak for this disaccharide split with no baseline separation. A likely explanation for this phenomenon is anomeric interconversion. Similar findings have been reported previously [13]. These authors found that interconversion between the $\alpha$ and $\beta$ forms occurred with one form predominating at increased temperature. In the present study significant interconversion was detected at $65^{\circ} \mathrm{C}$ but only minimal interconversion occured at $45^{\circ} \mathrm{C}$.

The effect of AMAC incubation time is shown in Figure 1e. As expected, the lowest LC-peak areas for all the disaccharides were observed at $2 \mathrm{~h}$. The LC-peak areas of the $\mathrm{N}$-substituted disaccharides peaked at $4 \mathrm{~h}$ with most of them decreasing thereafter. The exceptions to this trend were the $\mathrm{N}$-unsubstituted disaccharides with their LC-peak areas increasing with increased incubation time. The reason for this observation can be attributed to the loss of the labile N-sulfo group of the N-substituted GAG disaccharides with prolonged exposure to heat during derivatization. This resulted in the formation of the $\mathrm{N}$-unsubstituted disaccharides during derivatization with a resultant increase in their amounts. The N-unsubstituted disaccharides produced in this way cannot be distinguished from the ones originally present in the sample during separation and MS detection since they have the same mass and retention times.

In summary, the optimum AMAC derivatization conditions for this method is $0.210 \mu \mathrm{g}$ of AMAC with $4 \mathrm{~h}$ incubation at $45^{\circ} \mathrm{C}$.

\subsection{Optimization of MS conditions}

Initial MS conditions were as follows; desolvation temperature, cone voltage and extractor voltage were between $350^{\circ} \mathrm{C},-50 \mathrm{~V}$ and $-2.5 \mathrm{~V}$ respectively. Using these conditions, we were able to detect all thirteen derivatized HS disaccharides tested. The molecular weight and disaccharide ions detected using selected ion recording (SIR) of AMAC-derivatized heparin/HS disaccharides are shown in Table 1. For several of these, multiple ions were 
detected which represent loss of sulfonic groups which are likely to result from in-source fragmentation. It is notable that with a single exception the same disaccharide subunits that showed loss of sulfonic groups during high temperature derivatization above also show multiple ions during ionization. Figure $2 \mathrm{~b}$ also shows MS spectra for two of these ( $\triangle \mathrm{UA}, 2 \mathrm{~S}-$ GlcNS,6S and $\triangle U A, 2 S-G l c N A c, 6 S)$ confirming this. For others, only single ions were detected by MS. It was observed during optimization of derivatization conditions that certain disaccharides are more labile than others. Notably, doubly charged species were seen for disaccharides with more than one sulfate group. This can be explained by the loss of protons from disaccharides with two or more sulfonic acid groups and can be linked to the $\mathrm{pH}$ of the mobile phase.

Figure 2a shows the effect of different cone voltages (-15 to -75 V) on the LC-peak area of derivatized HS disaccharide subunits. The optimum voltage was found to be in the the range -20 to $-55 \mathrm{~V}$ depending on the subunit. Table 2 shows the optimal cone voltage for each subunit. These voltages were used in subsequent experiments. Lower cone voltages were optimum for lower $\mathrm{m} / \mathrm{z}$ values and vice versa. Optimum cone voltage may be impacted by many factors. In-source fragmentation is certainly an important factor here. In-source fragmentation at higher cone voltages in ESI-MS operated in the negative mode has previously been reported [25].

As a group, the disaccharides that were detected using their $[\mathrm{M}-2 \mathrm{H}]^{2-}$ species had lower $\mathrm{m} / \mathrm{z}$ values and required lower cone voltages for optimal signal intensities (LC-peak areas) with signal intensity decreasing with further increase in cone voltage. This can be explained by a reduction in in-source fragmentation thus preserving the parent ion, and promoting the formation of $[\mathrm{M}-2 \mathrm{H}]^{2-}$ species at a lower cone voltage. Notably, in-source fragmentation is promoted at high cone voltages. This is clearly seen in Figure $2 b$ using $\triangle U A, 2 S-$ GlcNS,6S and $\triangle \mathrm{UA}, 2 \mathrm{~S}$ - GlcNAc,6S at a higher concentration $(100 \mu \mathrm{g} / \mathrm{mL})$ as examples. The signal intensity of the other disaccharides detected using their $[\mathrm{M}-\mathrm{H}]^{-}$and $\left[\mathrm{M}-\mathrm{SO}_{3}-\mathrm{H}\right]^{-}$ species increased with increasing cone voltage, peaked, and decreased afterwards. The decrease most likely resulting from an increased in-source fragmentation of the monitored ion at higher cone voltages. Our results can be explained by both an increase in in-source fragmentation at higher cone voltages and differential ionization.

Figure $2 \mathrm{c}$ and $\mathrm{d}$ show the effect of extractor voltage and desolvation teemperature on signal intensity. It is clear that the optima are $3 \mathrm{~V}$ and $350^{\circ} \mathrm{C}$ respectively for all derivatized subunits. It can be seen that there is more efficient solvent evaporation with increasing temperature up to $350^{\circ} \mathrm{C}$. However, further temperature increase leads to in-source fragmentation and consequent loss of signal. This can clearly be seen in the spectra of $\triangle U A, 2 S$ - 
GlcNS,6S (Fig 2e). This was studied at a higher concentration and a cone voltage of $-60 \mathrm{~V}$ where fragmentation is promoted in order to show this. With increasing temperature, the ion assigned to $\triangle \mathrm{UA}, 2 \mathrm{~S}$ - GlcNS,6S with the loss of two sulfonic group ([M-2SO$\left.\left.{ }_{3}-\mathrm{H}\right]^{-}, \mathrm{m} / z 610\right)$ relative to that with the loss of one sulfonic group $\left(\left(\left[\mathrm{M}-\mathrm{SO}_{3}-\mathrm{H}\right]^{-}, \mathrm{m} / \mathrm{z} 690\right)\right.$ is increased.

\subsection{Chromatography of GAG subunits}

Based on these results further analysis was carried out using the optimum cone voltage for each derivatized $\mathrm{HS}$ disaccharide with an extractor voltage $-3 \mathrm{~V}$ and desolvation temperature of $350{ }^{\circ} \mathrm{C}$. From the MS analysis alone there were a number of disaccharides with $\mathrm{m} / \mathrm{z}$ values close to 610 ( $\triangle \mathrm{UA}, 2 \mathrm{~S}$ - GlcNS, $\Delta \mathrm{UA}-\mathrm{GlcNS}, 6 \mathrm{~S}, \Delta \mathrm{UA}-\mathrm{GlcNS}, \Delta \mathrm{UA}, 2 \mathrm{~S}-\mathrm{GlcN}$ and $\triangle \mathrm{UA}-\mathrm{GlcN}, 6 \mathrm{~S})$. In addition, $\triangle \mathrm{UA}, 2 \mathrm{~S}-\mathrm{GlcNAc}$ and $\triangle \mathrm{UA}-\mathrm{GlcNAc}, 6 \mathrm{~S}$ both had similar $\mathrm{m} / \mathrm{z}$ values ( 652). However, using the UPLC conditions described each of these eluted at a different retention time and each can be easily quantified. Figure 3 shows the single ion recording (SIR) chromatograms of a mixture of AMAC-derivatized HS disaccharides run using the optimized conditions described above. It was notable that the separation and quantification of the thirteen HS disaccharides was achieved within approximately $11 \mathrm{~min}$ with good LC-peak shape. We are not aware of any previous reports of LC-MS-based methods of GAG disaccharide analysis with such rapid analysis time. The run time of the current method is significantly shorter than previous studies of AMAC-derivatized GAG disaccharides LC-MS analysis. These have reported run times of 50-60 min [14, 24].

The derivatized disaccharides eluted in order of increasing hydrophobicity with the trisulfated disaccharide eluting first followed by di- and then mono-sulfated subunits and the non-sulfated subunits eluted last. The only exception to this was the mono-sulfated $\triangle U A-$ GlcNS which eluted within the retention window of the di-sulfated subunits. This order of elution has been reported previously [14]. It is interesting to note that within the elution window for di-sulfated disaccharides, those which are $\mathrm{N}$-sulfated eluted before those which are n-acetylated. This same pattern was also observed for the mono-sulfated subunits. This order of elution can also be explained by differences in hydrophobicity between n-sulfated and $n$-acetylated subunits. Differences in hydrophobicity may also explain the observation that, in general, $6 \mathrm{~S}$ sulfated subunits eluted prior to $2 \mathrm{~S}$ subunits.

The analysis of underivatized GAG disaccharides either by direct MS infusion or with specialized separation techniques including strong anion exchange [17], graphitized carbon LC [26] and HILIC columns [13] has been reported previously. The key advantage of these methods is that loss of disaccharides during derivatization is avoided but there are several disadvantages associated with direct analysis. Separation using graphitized carbon has been shown to affect the recovery of the trisulfated disaccharide because these species are 
disproportionally retained and co-elution of disaccharides has been reported with HILIC [13]. In addition, a sample solvent of high organic concentration is required for HILIC chromatography, which may result in solubility issues as GAG disaccharides are polar. With ion exchange chromatography, the zwitterionic nature of $\mathrm{N}$-unsubstituted disaccharides may result in poor retention [27]. Analysis of underivatized GAG disaccharides from commercially available GAG oligosaccharides and purified samples by tandem MS without LC separation has also been reported [28, 29, 30,31]. These methods are complex and require a relatively expensive tandem MS to achieve the collision induced dissociation (CID) necessary to yield diagnostic ions for the differentiation of sulfational positional isomers. In addition, many of these direct analysis methods may be significantly affected by the numerous substances present in biological samples if GAGs are not purified before analysis. Size exclusion chromatographic methods have also been reported for the analysis of underivatized GAG disaccharides [27, 32]. However, these methods also require tandem MS in order to resolve sulfational positional isomers which co-elute [13] in addition to long run times of over 100 minutes. A previous study has analysed GAG disaccharides from heparin sulphate using direct SEC-LC/MS and MS/MS also revealed $\triangle \mathrm{UA}-$ GlcNAc to be the most abundant disaccharide [32]. They found that 10 ug starting material was required in order to quantify disaccharides. However, the indirect LC/MS analysis with AMAC used in our study required only 5 ug starting material and required a significantly shorter rune time. Thus, our method overcomes these challenges and consequently a significantly shorter run time, good resolution and peak shape is achieved. In addition, there is no co-elution of disaccharides, the recovery of highly sulfated disaccharides is not problematic, and the relatively expensive tandem MS is not required. Derivatization with AMAC increases the hydrophobicity of these polar HS disaccharides. Increasing hydrophobicity increases ESI response as the hydrophobic ions have an increased affinity for the droplet surface thus entering the gas phase more readily [33, 34]. Hydrophobic analytes can also be well separated from potentially ion suppressing compounds and salts [34] thus reducing interference from any contaminating material that maybe be present in biological samples. Our method also permits UV/fluorescent detection due to AMAC derivatization thus can be adapted for use in laboratories without mass spectrometers.

\subsection{Method validation}

There was a clear linear relationship between the subunit concentration and the LC-peak area for each subunit across the range of concentrations tested $(0.02-10 \mu \mathrm{g} / \mathrm{mL})$. The limits 
of detection and quantification varied between different subunits (Table 3) and ranged from $0.02-0.15$ and $0.02-0.31 \mu \mathrm{g} / \mathrm{mL}$ respectively. The mono-sulfated $\triangle \mathrm{UA}, 2 \mathrm{~S}$ - GlcNAc showed the greatest ionization capacity with an LOD of $0.02 \mu \mathrm{g} / \mathrm{ml}$. The linearity $\left(r^{2}\right)$ of this method $(0.9747-1)$ is similar to previously reported [14], however, our LODs were higher. The precision (CV) of this method, based on five repeat measures at three concentrations ranged from $0.64-9.02 \%$ at $0.625 \mu \mathrm{g} / \mathrm{mL}, 0.54-3.20 \%$ at $1.25 \mu \mathrm{g} / \mathrm{mL}$, and $0.39-1.57 \%$ at $5 \mu \mathrm{g} / \mathrm{mL}$. There was little variation between disaccharide subunits but the precision was lowest at lower concentrations. This precision is within the range $(<15 \%)$ accepted by the US Food and Drug Administration (FDA) and European Medicines Agency (EMA) for bioanalytical methods [35, 36]

Table 4 shows the recovery of heparan sulfate disaccharides following extraction of HS as described in the methods. Six subunits were quantifiable from HS after extraction. As expected, the recovery is better with higher amounts of starting material $(10 \mu \mathrm{g})$ compared to $5 \mu \mathrm{g}$ irrespective of disaccharide. The highest disaccharide recovery is seen for $\triangle \mathrm{UA}-$ GIcNAc as expected because it is the most abundant disaccharide seen in the HS standard. This bias in recovery may influence the compositional analysis of the disaccharides recovered from different sources. The reason for this poor recovery may be linked to the numerous steps involved in the extraction, depolymerization, and derivatization of these GAG disaccharides.

\subsection{Heparin/HS disaccharide composition of HS standard and cell lines}

We found that the non-sulfated $\triangle U A-G I C N A C$ was the most abundant disaccharide present in HS standard comprising, about half of all disaccharide subunits (Fig 5, Table 4). $\triangle \mathrm{UA}-$ GlcNAc,6S comprised about $20 \%$ of $\mathrm{HS}$ and the disaccharides $\triangle \mathrm{UA}, 2 \mathrm{~S}-\mathrm{GlcNS}$ and $\triangle \mathrm{UA}, 2 \mathrm{~S}-\mathrm{GlcNAc}$ were the least abundant representing 0.5 and $0.7 \%$ respectively. Compositional analysis of porcine intestinal mucosal HS by fluorescent and UV detection of heparan sulfate was previously carried by Deakin \& Lyon [17]. They also found that $\triangle U A-$ GlcNAc was the most abundant disaccharide. Our other results were in broad agreement; the only exceptions being that we have found much higher levels of $\triangle \mathrm{UA}-\mathrm{GlcNAc}, 6 \mathrm{~S}$ and much lower concentrations of $\triangle \mathrm{UA}-\mathrm{GlcNS}, 6 \mathrm{~S}$ (21.8\% and $12 \%$ respectively, Table 5). We were also able to detect an additional disaccharide not seen in the other study ( $\triangle \mathrm{UA}, 2 \mathrm{~S}-$ GlcNAc). An advantage of our method is the use of a combination of retention time and $\mathrm{m} / \mathrm{z}$ that provides an unequivocal identification of each HS disaccharide. In addition, we believe that the additional use of an internal standard improved reproducibility between runs. Finally, we have used single ion monitoring for each disaccharide. This selective approach may also enhance sensitivity. Thus, this difference may be due to the increased sensitivity of our 
method or the difference in the source of HS as we used HS from bovine kidney. The relative abundance of disaccharides present in heparan sulfate is also broadly in agreement with that reported by Gill et al. [13] with the non-sulfated $\triangle U A-G l c N A c$ and monosulfated $\triangle U A-$ GlcNAc,6S as the most abundant disaccharides present. However, we found that the disulfated $\triangle U A, 2 S-G l c N S$ was significantly less common $(0.5 \%$ of total) compared to previous reports (8.3\% of total, [13]).

In comparison to the HS the cell lines generally comprised significantly less of the nonsulfated HS disaccharide $\triangle \mathrm{UA}-\mathrm{GICNAc}$ and the trisulfated $\triangle \mathrm{UA}, 2 \mathrm{~S}-\mathrm{GlcNS}, 6 \mathrm{~S}$. We are unaware of any previous reports quantifying expression of specific HS disaccharides in human cell lines. However, the composition of HS disaccharides in this study was broadly in agreement with a previous report that has examined expression from a canine kidney cell line (MDCK) [18] in that the most abundant cell line was $\triangle U A$ - GlcNAc. However, their study did not examine the absolute concentrations of HS disaccharides. There were significant differences in the heparan sulfate disaccharide composition between the various cell lines tested. For the majority of cell lines the non-sulfated $\triangle U A-G I C N A c$ was the most abundant disaccharide (Fig 4, Table 5) as is also the case for heparan sulfate itself. The only exception to this was in the breast cancer cell line MDA-468 where the monosulfated $\triangle U A-$ GIcNAc,6S had a slightly higher concentration.

Many studies have demonstrated regulatory effects of glycosaminoglycans on cell function including proliferation, differentiation and invasion [3, 37, 38]. In addition, several studies have examined the effects of specific HS and CS disaccharides on cell function. Poh et al. [39] found that CS disaccharides inhibit aggressive triple negative breast cancer cell viability. Previous studies have reported that addition of specific HS disaccharides, notably monosulfated $\triangle U A$-GIcNS significantly increased the production of the hepatocyte growth factor (HGF) in vitro and in vivo [40, 41]. HGF is known to contribute to the tumorogenic phenotype in many cancers and it is interesting to note that relative expression of this disaccharide was elevated in many of the cancer cell lines tested here compared to HS. In order to understand how specific disaccharide expression may be associated with tumour development it will be useful to apply the methodology described here to compare their expression in tissues from various cancer stages and with tissues from unaffected individuals. 


\subsection{Conclusion}

We have used this methodology to show the rapid separation and detection of AMAC derivatized heparan sulfate disaccharides with a total run time of only $18 \mathrm{~min}$. The method employed SIR in contrast to the commonly used TIC methods. Extracted ion chromatograms have been shown to be about 10 times more sensitive than TIC. We have shown that there are differences in both the total amount and composition of disaccharides between different tissue types. Further studies are needed to examine the significance of these differences. 


\section{References}

[1] E. Forsberg, G. Pejler, M. Ringvall, C. Lunderius, B. Tomasini-Johansson, M. Kusche-Gullberg, I. Eriksson, J. Ledin, L. Hellman and L. Kjellén, Abnormal mast cells in mice deficient in a heparinsynthesizing enzyme, Nature. 400:6746 (1999) 773-776.

[2] K. R. Taylor and R. L. Gallo, Glycosaminoglycans and their proteoglycans: host-associated molecular patterns for initiation and modulation of inflammation, FASEB J. 20 (2006) 9-22.

[3] F. A. Hills, V. M. Abrahams, B. González-Timón, J. Francis, B. Cloke, L. Hinkson, R. Rai, G. Mor, L. Regan, M. Sullivan, E. W.-F.Lam and J. J.Brosens, "Heparin prevents programmed cell death in human trophoblast," Mol. Hum. Reprod. 12: 4 (2006) 237-243.

[4] G. W. Yip, M. Smollich and M. Götte, "Therapeutic value of glycosaminoglycans in cancer, Mol Cancer Ther. 5:9 (2006) 2139-2148.

[5] F. Louwen, C. Muschol-Steinmetz, J. Reinhard, A. Reitter and J. Yuan, A lesson for cancer research: placental microarray gene analysis in preeclampsia, Oncotarget. 3:8 (2012) 759-772.

[6] B. Casu, A. Naggi and G. Torri, Heparin-derived heparan sulfate mimics to modulate heparan sulfate-protein interaction in inflammation and cancer., Matrix Biol. 29:6 (2010) 442-452.

[7] P. C. Billings and M. Pacifici, Interactions of signaling proteins, growth factors and other proteins with heparan sulfate: mechanisms and mysteries, Connect Tissue Res. 56:4 (2015) 272280.

[8] S. Sarrazin, W. C. Lamanna and J. D. Esko, Heparan Sulfate Proteoglycans, Cold Spring Harb Perspect Biol. 3: 7 (2011) a004952.

[9] E. P. Schmidt, G. Li, L. Li, L. Fu, Y. Yang, K. H. Overdier, I. S. Douglas and R. J. Linhardt, The Circulating Glycosaminoglycan Signature of Respiratory Failure in Critically III Adult, The Journal of Biological Chemistry. 289:12 (2014) 8194-8202.

[10] J. M. Beaudet, L. Mansur, E. J. Joo, E. Kamhi, B. Yang, T. M. Clausen, A. Salanti, F. Zhang and R. J. Linhard, Characterization of human placental glycosaminoglycans and regional binding to VAR2CSA in malaria infected erythrocytes, Glycoconj J. vol. 31:2 (2014) 109-116.

[11] A. Weyers, B. Yang, J.-H. Park, Y.-S. Kim, S.-M. Kim, S.-E. Lee, F. Zhang, K. B. Lee and R. J. Linhardt, Microanalysis of stomach cancer glycosaminoglycans, Glycoconj J. 30 (2013) 701-707.

[12] R. M. Schowalter, D. V. Pastrana and C. B. Buck, Glycosaminoglycans and Sialylated Glycans Sequentially Facilitate Merkel Cell Polyomavirus Infectious Entry, PLoS Pathogens. 7: 7 (2011) e1002161. 
[13] V. L. Gill, U. Aich, S. Rao, C. Pohl and J. Zaia, Disaccharide Analysis of Glycosaminoglycans Using Hydrophilic Interaction Chromatography and Mass Spectrometry, Anal Chem. 85:2 (2013) 1138-1145.

[14] B. Yang, Y. Chang, A. M. Weyers, E. Sterner and R. J. Linhardt, Disaccharide analysis of glycosaminoglycan mixtures by ultra-performance liquid chromatography-mass spectrometry, $J$ Chromatogr A. 1225 (2012) 91-98.

[15] G. Li, L. Li, F. Tian, L. Zhang, C. Xue and R. J. Linhardt, Glycosaminoglycanomics of Cultured Cells Using a Rapid and Sensitive LC-MS/MS Approach, ACS Chemical Biology. 10:5 (2015) 1303-1310.

[16] C. Hansen, R. Rouhi, G. Förster and G. J. Kahaly, Increased Sulfatation of Orbital Glycosaminoglycans in Graves' Ophthalmopathy, JCE \& M. 84:4 (1999) 1409-1413.

[17] J. A. Deakin and M. Lyon, A simplified and sensitive fluorescent method for disaccharide analysis of both heparan sulfate and chondroitin/dermatan sulfates from biological samples, Glycobiology. 16:6 (2008) 483-491.

[18] B. Kuberan, M. Lech, L. Zhang, Z. L. Wu, D. L. Beeler and R. D. Rosenberg, Analysis of heparan sulfate oligosaccharides with ion pair-reverse phase capillary high performance liquid chromatography-microelectrospray ionization time-of-flight mass spectrometry, J Am Chem Soc. 124:29 (2002) 8707 - 8718.

[19] C. E. Doneanu, W. Chen and J. C. Gebler, Analysis of Oligosaccharides Derived from Heparin by Ion-Pair Reversed-Phase Chromatography/Mass Spectrometry, Anal. Chem. 81 (2009) 34853499.

[20] K. Solakyildirim, Z. Zhang and R. J. Linhardt, Ultraperformance Liquid Chromatography with Electrospray Ion Trap Mass Spectrometry for Chondroitin Disaccharide Analysis, Analytical Biochemistry, 397 (2010)24-28.

[21] Y. Chang, B. Yang, X. Zhao and R. J. Linhardt, Analysis of glycosaminoglycan-derived disaccharides by capillary electrophoresis using laser-induced fluorescence detection, Analytical Biochemistry. 427 (2012) 91-98.

[22] E. Karousou, A. Asimakopoulou, L. Monti, V. Zafeiropoulou, N. Afratis, P. Gartaganis, A. Rossi, A. Passi and N. K. Karamanos, FACE Analysis as a Fast and Reliable Methodology to Monitorthe Sulfation and Total Amount of Chondroitin Sulfate in Biological Samples of Clinical Importance, Molecules. 19 (2014) 7959-7980.

[23] J. Han, F. Zhang, J. Xie, R. J. Linhardt and L. M. Hiebert, "Changes in cultured endothelial cell glycosaminoglycans under hyperglycemic conditions and the effect of insulin and heparin," Cardiovascular Diabetology. 8 (2009) 46.

[24] N. Volpi, F. Galeotti, B. Yang and R. J. Linhardt, Analysis of glycosaminoglycan-derived, precolumn, 2-aminoacridone-labeled disaccharides with LC-fluorescence and LC-MS detection, 
Nat Protoc. 9: 3 (2014) 541-558.

[25] E. A. A. M. Vernooij, J. F. H. M. K.-v.-d.-B. J. J. Brouwers and D. J. A. Crommelin, RP-HPLC/ESI MS determination of acyl chain positions in phospholipids, J. Sep. Sci. 25 (2002) 285-289.

[26] V. L. Gill, Q. Wang, X. Shi and J. Zaia, Mass Spectrometric Method for Determining the Uronic Acid Epimerization in Heparan Sulfate Disaccharides Generated using Nitrous Acid, Anal Chem. 84:17 (2012) 7539-7546.

[27] X. Shi and J. Zaia, Organ-specific Heparan Sulfate Structural Phenotypes, J Biol Chem. 284:18 (2009) 11806-11814.

[28] J. Zaia and C. E. Costello, Compositional analysis of glycosaminoglycans by electrospray mass spectrometry, Anal Chem. 73:2 (2001) 233-239.

[29] O. M. Saad, H. Ebel, K. Uchimura, S. D. Rosen, C. R. Bertozzi and J. A. Leary, Compositional profiling of heparin/heparan sulfate using mass spectrometry: assay for specificity of a novel extracellular human endosulfatase, Glycobiology. 15:8 (2005) 818-826,.

[30] O. M. Saad and J. A. Leary, Heparin sequencing using enzymatic digestion and ESI-MSn with HOST: a heparin/HS oligosaccharide sequencing tool, Anal Chem. 77:18 (2005) 5902-5911.

[31] C. Flangea, C. Schiopu, E. Sisu, A. Serb, M. Przybylski, D. G. Seidler and A. D. ZamfirEm, Determination of sulfation pattern in brain glycosaminoglycans by chip-based electrospray ionization ion trap mass spectrometry, Analytical and Bioanalytical Chemistry. 395 (2009) 2489.

[32] G. O. Staples, X. Shi and a. J. Zaia, Glycomics Analysis of Mammalian Heparan Sulfates Modified by the Human Extracellular Sulfatase HSulf2, PLoS One. 6:2 (2011) p. e16689.

[33] A. Nordstrom, P. Tarkowski, D. Tarkowska, K. Dolezal, C. Astot, G. Sandberg and T. Moritz, Derivatization for LC-Electrospray lonization-MS: A Tool for Improving Reversed-Phase Separation and ESI Responses of Bases, Ribosides, and Intact Nucleotides, Anal. Chem. 76 (2004) 2869-2877.

[34] T. Santa, O. Y. Al-Dirbashi and T. Fukushima, Derivatization reagents in liquid chromatography/electrospray ionization tandem mass spectrometry for biomedical analysis, Drug Discov Ther. 1:2 (2007) 108-118.

[35] U.S. Food and Drug Administration, Guidance for Industry: Bioanalytical Method Validation. http://www.fda.gov/downloads/Drugs/Guidance/ucm070107.pdf. 2001 (accessed 06.01.16).

[36] European Medicines Agency, Guideline on bioanalytical method validation, http://www.ema.europa.eu/docs/en_GB/document_library/Scientific_guideline/2011/08/WC5 00109686.pdf. 2011 (accessed 06.01.16].

[37] V. Friand, O. Haddad, D. Papy-Garcia, H. Hlawaty, H.-K. Y. Vassy R, G. Y. Perret, J. Courty, F. Baleux, O. Oudar, L. Gattegno, A. Sutton and N. Charnaux, Glycosaminoglycan mimetics inhibit 
SDF-1/CXCL12-mediated migration and invasion of human hepatoma cells, Glycobiology. 19:12 (2009) 1511 - 1524.

[38] A. Xiong, S. Kundu and K. Forsberg-Nilsson, "Heparan sulfate in the regulation of neural differentiation and glioma development," FEEBS J. 281:22 (2014) 4993 - 5008.

[39] Z. W. Poh, C. H. Gan, E. J. Lee, S. Guo, G. W. Yip and Y. Lam, Divergent Synthesis of Chondroitin Sulfate Disaccharides and Identification of Sulfate Motifs that Inhibit Triple Negative Breast Cancer, Scientific Reports. 5 (2015)14355.

[40] R. Sakiyama, K. Fukuta, K. Matsumoto, M. Furukawa, Y. Takahashi and T. Nakamura, Stimulation of hepatocyte growth factor production by heparin-derived oligosaccharides, J Biochem. 141 (2007) 653-660.

[41] T. Kato, R. Sakiyama, K. Oka and T. Nakamura, Identification of core active disaccharides in heparin for HGF-inducing activity, J Pharmacol Pharmacother. 6:2 (2015) 77-82. 


\section{ACCEPTED MANUSCRIPT}

Table 1: Heparin/HS disaccccharide structural codes, MS ions, and assigniment. Extractor voltage: $3 \mathrm{~V}$, and desolvation temperature: $350^{\circ} \mathrm{C}$. MS ions in bold were the most intense seen and used for DS MS detection.

\begin{tabular}{|c|c|c|}
\hline HS DS structural code & MS ion (DS + AMAC) & Assignment \\
\hline \multirow{6}{*}{$\Delta \mathrm{UA,2S}$-GIcNS,6S } & 769.9 & {$[\mathrm{M}-\mathrm{H}]^{-}$} \\
\hline & 690.2 & {$\left[\mathrm{M}-\mathrm{SO}_{3}-\mathrm{H}\right]^{-}$} \\
\hline & 610.0 & {$\left[\mathrm{M}-2 \mathrm{SO}_{3}-\mathrm{H}\right]^{-}$} \\
\hline & 384.5 & {$[\mathrm{M}-2 \mathrm{H}]^{2-}$} \\
\hline & 344.5 & {$\left[\mathrm{M}-\mathrm{SO}_{3}-2 \mathrm{H}\right]^{2-}$} \\
\hline & 304.7 & {$\left[\mathrm{M}-2 \mathrm{SO}_{3}-2 \mathrm{H}\right]^{2-}$} \\
\hline \multirow[t]{4}{*}{$\Delta U A, 2 S$ - GIcNS } & 690.2 & {$[\mathrm{M}-\mathrm{H}]^{-}$} \\
\hline & 610.0 & {$\left[\mathrm{M}^{-\mathrm{SO}_{3}-\mathrm{H}}\right]^{-}$} \\
\hline & 344.0 & {$[\mathrm{M}-2 \mathrm{H}]^{2-}$} \\
\hline & 304.5 & {$\left[\mathrm{M}-\mathrm{SO}_{3}-2 \mathrm{H}\right]^{2-}$} \\
\hline \multirow[t]{3}{*}{$\triangle \mathrm{UA,2S}$ - GIcNAc,6S } & 732.3 & {$[\mathrm{M}-\mathrm{H}]^{-}$} \\
\hline & 652.4 & {$\left[\mathrm{M}-\mathrm{SO}_{3}-\mathrm{H}\right]^{-}$} \\
\hline & 365.7 & {$[\mathrm{M}-2 \mathrm{H}]^{2-}$} \\
\hline \multirow[t]{4}{*}{$\Delta \mathrm{UA}-\mathrm{GIcNS}, 6 \mathrm{~S}$} & 690.1 & {$[\mathrm{M}-\mathrm{H}]^{-}$} \\
\hline & 610.0 & {$\left[\mathrm{M}^{-\mathrm{SO}_{3}}-\mathrm{H}\right]^{-}$} \\
\hline & 344.0 & {$[\mathrm{M}-2 \mathrm{H}]^{2-}$} \\
\hline & 304.5 & {$\left[\mathrm{M}-\mathrm{SO}_{3}-2 \mathrm{H}\right]^{2-}$} \\
\hline$\Delta U A-G I c N S$ & 610.3 & {$[\mathrm{M}-\mathrm{H}]^{-}$} \\
\hline$\Delta U A-G I c N A c$ & 572.3 & {$[\mathrm{M}-\mathrm{H}]^{-}$} \\
\hline$\Delta U A, 2 S$ - GIcNAC & 652.3 & {$[\mathrm{M}-\mathrm{H}]^{-}$} \\
\hline$\Delta \mathrm{UA}$ - GIcNAc,6S & 652.2 & {$[\mathrm{M}-\mathrm{H}]^{-}$} \\
\hline$\triangle \mathrm{UA}, 2 \mathrm{~S}$ - GIcNCOEt, 6S & 372.6 & {$[\mathrm{M}-2 \mathrm{H}]^{2-}$} \\
\hline$\Delta \mathrm{UA,2S}-\mathrm{GICN}$ & 610.3 & {$[\mathrm{M}-\mathrm{H}]^{-}$} \\
\hline$\Delta \mathrm{UA}, 2 \mathrm{~S}-\mathrm{GIcN}, 6 \mathrm{~S}$ & 344.6 & {$[\mathrm{M}-2 \mathrm{H}]^{2-}$} \\
\hline$\Delta U A-G I c N, 6 S$ & 610.2 & {$[\mathrm{M}-\mathrm{H}]^{-}$} \\
\hline$\Delta \mathrm{UA}-\mathrm{GIcN}$ & 530.2 & {$[\mathrm{M}-\mathrm{H}]^{-}$} \\
\hline
\end{tabular}


Table 2: Optimal cone voltage for the different heparin/HS DS

\begin{tabular}{|c|c|}
\hline HS DS subunit & Optimal cone voltage (-V) \\
\hline$\Delta \mathrm{UA}, 2 \mathrm{~S}-\mathrm{GlcNS}, 6 \mathrm{~S}$ & 20 \\
\hline$\Delta \mathrm{UA}, 2 \mathrm{~S}-\mathrm{GlcNS}$ & 55 \\
\hline$\Delta U A, 2 S-$ GlcNAc,6S & 25 \\
\hline$\Delta \mathrm{UA}-\mathrm{GlcNS}, 6 \mathrm{~S}$ & 55 \\
\hline$\Delta U A-G l c N S$ & 55 \\
\hline$\Delta U A-G l c N A c$ & 50 \\
\hline$\Delta U A, 2 S-G I c N A c$ & 55 \\
\hline$\Delta U A-$ GlcNAc,6S & 55 \\
\hline$\Delta \mathrm{UA}, 2 \mathrm{~S}-\mathrm{GlcN}$ & 50 \\
\hline$\Delta \mathrm{UA}, 2 \mathrm{~S}-\mathrm{GlcN}, 6 \mathrm{~S}$ & 20 \\
\hline$\Delta \mathrm{UA}-\mathrm{GlcN}, 6 \mathrm{~S}$ & 55 \\
\hline$\Delta U A-G l c N$ & 50 \\
\hline
\end{tabular}


Table 3: Monitored MS ions, retention time, limits of detection, limits of quantitation, $\mathrm{r}^{2}$, slope, and intercept of the method. LOD and LOQ were determined using signal:noise 3:1 and 10:1 respectively.

\begin{tabular}{|c|c|c|c|c|c|c|c|}
\hline $\begin{array}{l}\text { HS DS structural } \\
\text { code }\end{array}$ & $\begin{array}{l}\text { Monitored } \\
\text { MS ion } \\
(\mathrm{m} / \mathrm{z})\end{array}$ & $\begin{array}{l}\text { Retention } \\
\text { time } \\
\text { (min) }\end{array}$ & $\begin{array}{l}\text { LOD } \\
(\mu \mathrm{g} / \mathrm{ml})\end{array}$ & $\begin{array}{c}\mathrm{LOQ} \\
(\mu \mathrm{g} / \mathrm{ml})\end{array}$ & $\mathbf{r}^{2}$ & Slope & Intercept \\
\hline$\Delta \mathrm{UA}, 2 \mathrm{~S}-\mathrm{GlcNS}, 6 \mathrm{~S}$ & 384.5 & 2.5 & 0.07 & 0.11 & 0.9999 & 1269.6 & -83.46 \\
\hline$\Delta U A, 2 S-G l c N S$ & 610.0 & 4.0 & 0.08 & 0.14 & 0.9998 & 1955.1 & -124.63 \\
\hline $\begin{array}{l}\Delta \mathrm{UA}, 2 \mathrm{~S}- \\
\text { GlcNAc,6S }\end{array}$ & 365.7 & 6.1 & 0.09 & 0.18 & 0.9999 & 1720.2 & -115.7 \\
\hline$\Delta \mathrm{UA}-\mathrm{GlcNS}, 6 \mathrm{~S}$ & 610.0 & 3.2 & 0.08 & 0.17 & 0.9999 & 1947.9 & -79.96 \\
\hline$\Delta \mathrm{UA}-\mathrm{GlcNS}$ & 610.3 & 5.4 & 0.12 & 0.17 & 0.9993 & 2457.7 & -243.67 \\
\hline$\Delta U A-$ GlcNAc & 572.3 & 10.1 & 0.06 & 0.09 & 0.9998 & 3051.4 & -150.75 \\
\hline$\triangle \mathrm{UA}, 2 \mathrm{~S}-\mathrm{GlcNAc}$ & 652.3 & 8.7 & $<0.02$ & 0.02 & 0.9999 & 12007 & 144.94 \\
\hline$\Delta U A-$ GlcNAc,6S & 652.2 & 7.6 & 0.13 & 0.19 & 0.9997 & 2756.2 & -357.42 \\
\hline $\begin{array}{c}\Delta \mathrm{UA}, 2 \mathrm{~S}- \\
\text { GlcNCOEt, } 6 \mathrm{~S}\end{array}$ & 372.6 & 8.3 & 0.07 & 0.13 & 1 & 2678.5 & -130.26 \\
\hline$\Delta U A, 2 S-G l c N$ & 610.3 & 8.0 & 0.15 & 0.31 & 0.9747 & 1031.3 & 386.21 \\
\hline$\Delta \mathrm{UA}, 2 \mathrm{~S}-\mathrm{GlcN}, 6 \mathrm{~S}$ & 344.6 & 5.8 & 0.15 & 0.31 & 0.9785 & 686.75 & 262.55 \\
\hline$\Delta \mathrm{UA}-\mathrm{GlcN}, 6 \mathrm{~S}$ & 610.2 & 7.2 & 0.15 & 0.31 & 0.9876 & 1435.3 & 303.37 \\
\hline$\Delta U A-G l c N$ & 530.2 & 9.4 & 0.15 & 0.31 & 0.9843 & 1381.2 & 341.58 \\
\hline
\end{tabular}


Table 4: Recovery of Hep/HS DS following digestion, derivatization, and separation using the final protocol described above.

\begin{tabular}{|c|c|c|c|c|c|c|}
\hline \multicolumn{7}{|c|}{ Recovery (\%) } \\
\hline $\begin{array}{c}\text { HS standard } \\
(\mu \mathrm{g})\end{array}$ & $\begin{array}{l}\triangle U A, 2 S- \\
\text { GIcNS,6S }\end{array}$ & $\begin{array}{c}\triangle U A 2 S- \\
\text { GIcNS }\end{array}$ & $\begin{array}{c}\Delta U A- \\
\text { GIcNS,6S }\end{array}$ & $\begin{array}{l}\triangle U A- \\
\text { GICNS }\end{array}$ & $\begin{array}{l}\triangle U A- \\
\text { GICNAC }\end{array}$ & $\begin{array}{c}\Delta U A- \\
\text { GIcNAc,6S }\end{array}$ \\
\hline 5 & 26.32 & 33.33 & 18.18 & 27.78 & 42.86 & 24.14 \\
\hline 10 & 26.67 & 35.71 & 30.77 & 39.02 & 43.02 & 33.33 \\
\hline
\end{tabular}


Table 5. Composition of discaccahride subunits present in the cell lines tested. Top panel indicates concentrations ( $\mathrm{ng} / \mathrm{mg}$ dry weight). Bottom panel represents the relative abundance expressed as a percentage of total for each cell line.

\begin{tabular}{|l|c|c|c|c|c|}
\hline \multicolumn{1}{|c|}{$\mathrm{ng} / \mathrm{mg}$ dry weight } \\
\hline \multicolumn{1}{|c|}{ DS subunit } & OVCAR & MOLM-13 & MDA-468 & HCT-116 & BeWo \\
\hline$\Delta U A, 2 S-G I c N S, 6 S$ & $241.2(3.11)$ & $1197.5(5.19)$ & $110.2(5.22)$ & $256.0(3.49)$ & $203.9(0.27)$ \\
\hline$\Delta U A, 2 S-G I c N S$ & $97.0(5.76)$ & $235.6(6.32)$ & ND & $78.2(1.69)$ & ND \\
\hline$\Delta U A-G I c N S, 6 S$ & $74.9(1.42)$ & $84.0(14.48)$ & $61.7(1.46)$ & $98.4(2.67)$ & $65.2(2.24)$ \\
\hline$\Delta U A-G I c N S$ & $210.8(8.86)$ & $252.6(14.11$ & $109.9(2.08)$ & $153.3(1.56)$ & $197.9(2.66)$ \\
\hline$\Delta U A-G I c N A c$ & $309.0(3.95)$ & $1095.1(99.68)$ & $121.3(0.47)$ & $259.8(2.63)$ & $326.9(3.39)$ \\
\hline$\Delta U A, 2 S-G I c N A c$ & $11.6(0.63)$ & $14.1(0.40)$ & ND & ND & $4.2(0.94)$ \\
\hline$\Delta U A-G I c N A c, 6 S$ & $113.2(1.31)$ & $177.0(0.67)$ & $150.9(7.04)$ & $180.8(4.80)$ & $90.6(0.95)$ \\
\hline Total & $\mathbf{1 0 5 8 ( 3 . 5 8 )}$ & $\mathbf{3 0 5 6 ( 7 . 2 6 )}$ & $\mathbf{5 5 4 ( 3 . 2 5 )}$ & $\mathbf{1 0 2 7 ( 2 . 8 1 )}$ & $\mathbf{8 8 9 ( 1 . 7 4 )}$ \\
\hline
\end{tabular}

\begin{tabular}{|l|c|c|c|c|c|c|}
\hline \multicolumn{1}{|c|}{ \% total for cell line } & & \\
\hline \multicolumn{1}{|c|}{ DS subunit } & OVCAR & MOLM-13 & MDA-468 & HCT-116 & BeWo & HS \\
\hline$\Delta$ UA,2S-GIcNS,6S & $22.8(0.29)$ & $39.2(0.17)$ & $19.9(0.94)$ & $24.9(0.34)$ & $22.9(0.03)$ & $8.2(0.10)$ \\
\hline$\Delta U A, 2 S-G I c N S$ & $9.2(0.55)$ & $7.7(0.21)$ & ND & $7.6(0.16)$ & ND & $0.5(0.01)$ \\
\hline$\Delta U A-G I c N S, 6 S$ & $7.1(0.13)$ & $2.7(0.47)$ & $11.1(0.26)$ & $9.6(0.26)$ & $7.3(0.25)$ & $8.7(0.23)$ \\
\hline$\triangle U$ UA-GIcNS & $19.9(0.84)$ & $8.3(0.46)$ & $19.8(0.37)$ & $14.9(0.15)$ & $22.3(0.30)$ & $12.6(0.38)$ \\
\hline$\triangle U A-G I c N A c$ & $29.2(0.37)$ & $35.8(0.32)$ & $21.9(0.08)$ & $25.3(0.26)$ & $36.8(0.38)$ & $48.0(0.44)$ \\
\hline$\triangle U A, 2 S-G I c N A c$ & $1.1(0.06)$ & $0.5(0.01)$ & ND & ND & $0.5(0.11)$ & $0.7(0.01)$ \\
\hline$\triangle U A-G I c N A c, 6 S$ & $10.7(0.12)$ & $5.8(0.02)$ & $27.2(1.27)$ & $17.6(0.47)$ & $10.2(0.11)$ & $21.3(0.19)$ \\
\hline
\end{tabular}




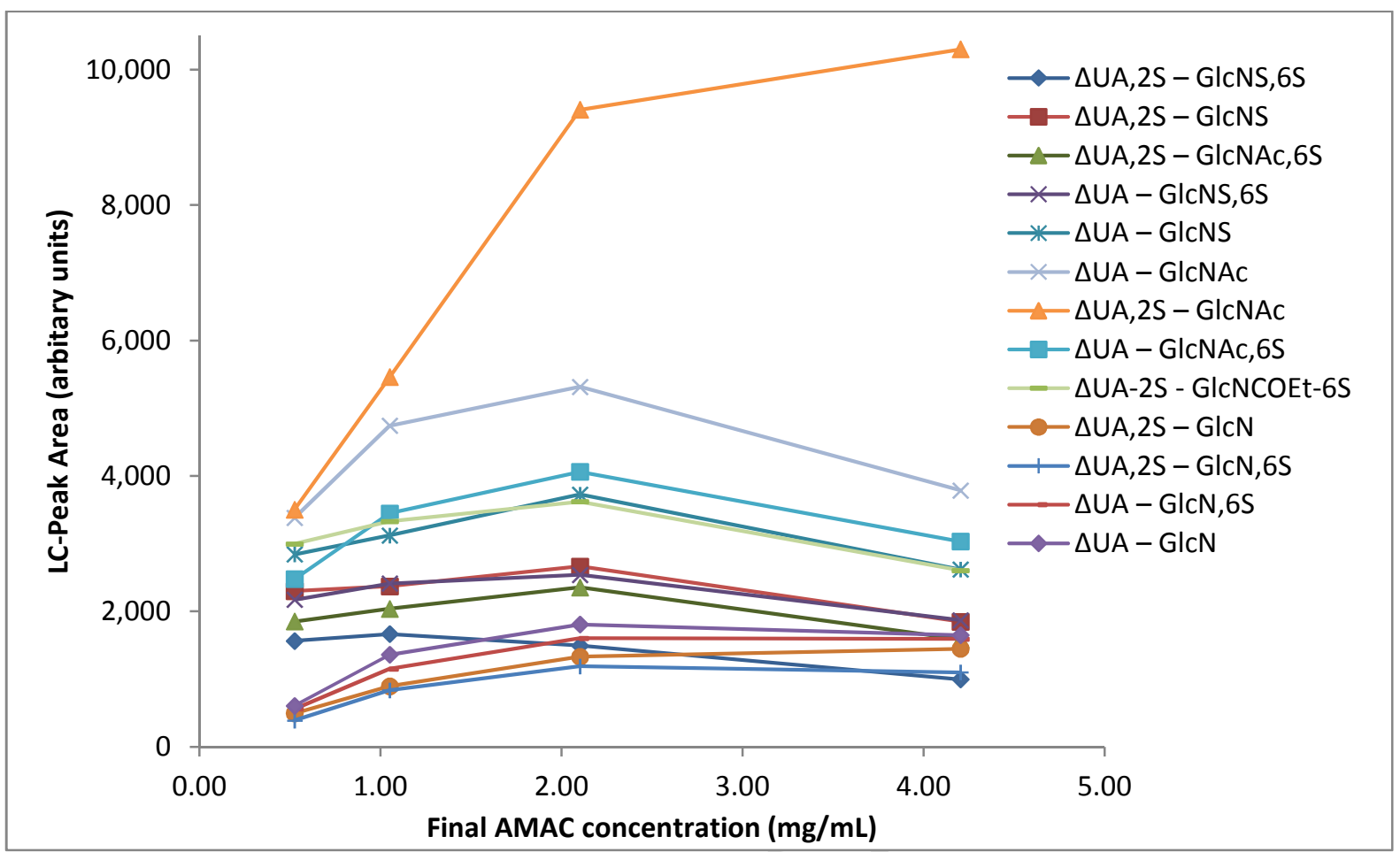

Figure 1a: LC-peak area as a function of the concentration of AMAC used for derivatization. Heparin/HS DS concentration: $2.5 \mu \mathrm{g} / \mathrm{mL}$.

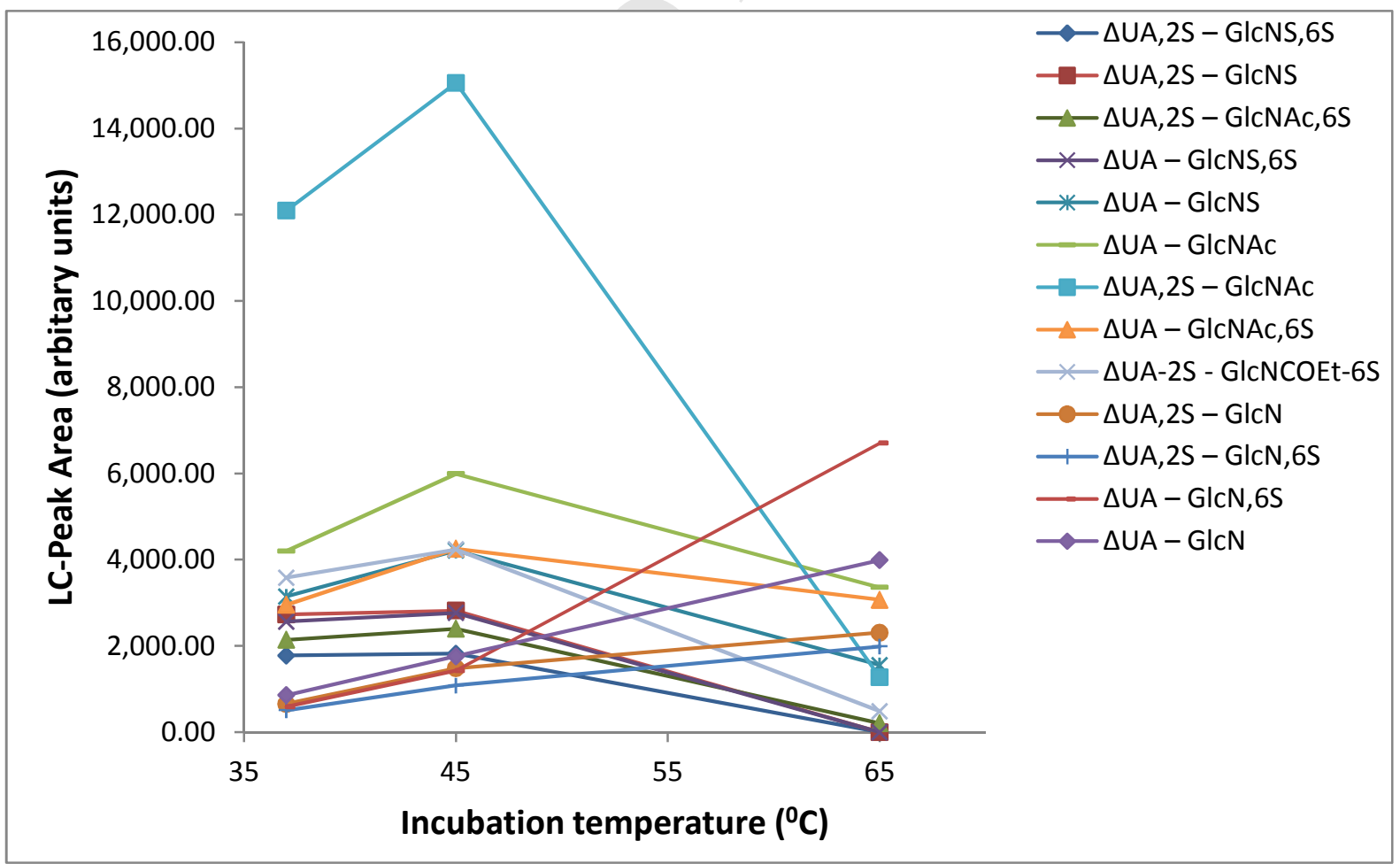

Figure 1b: LC-peak area as a function of derivatization temperature of AMAC-derivatized heparin/HS DS standard. Heparin/HS DS concentration: $2.5 \mu \mathrm{g} / \mathrm{mL}$. 

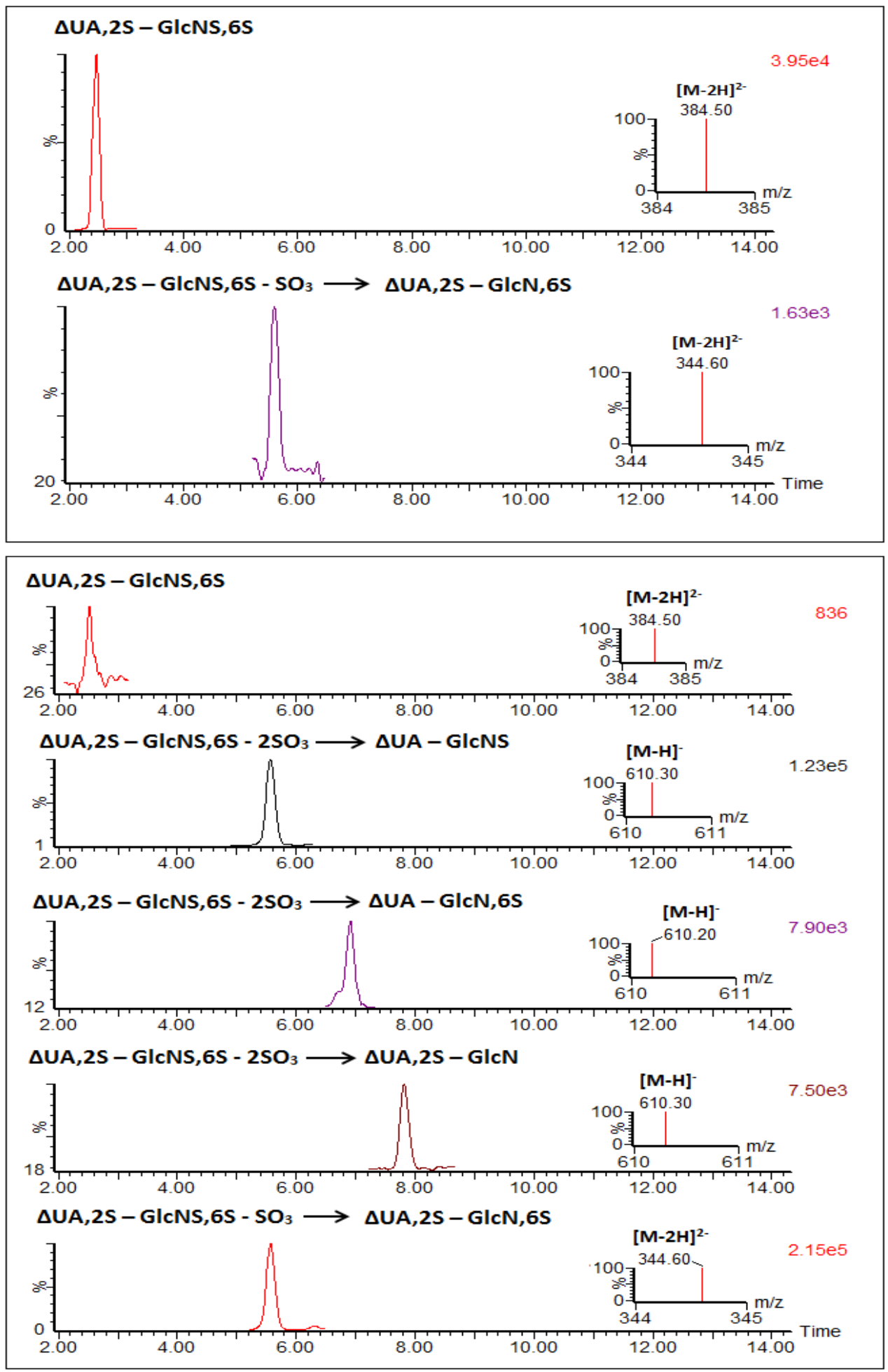

Figure 1c: Selected ion recording (SIR) chromatogram of AMAC-derivatized $\triangle \mathrm{UA}, 2 \mathrm{~S}-$ GlcNS,6S derivatized at $45{ }^{\circ} \mathrm{C}$ (top box) and $65{ }^{\circ} \mathrm{C}$ (bottom box) for $4 \mathrm{~h}$ showing loss of $\mathrm{SO}_{3}{ }^{-}$ groups resulting in the formation of other DS during derivatization. Injection vol. $3 \mu \mathrm{L}$ 

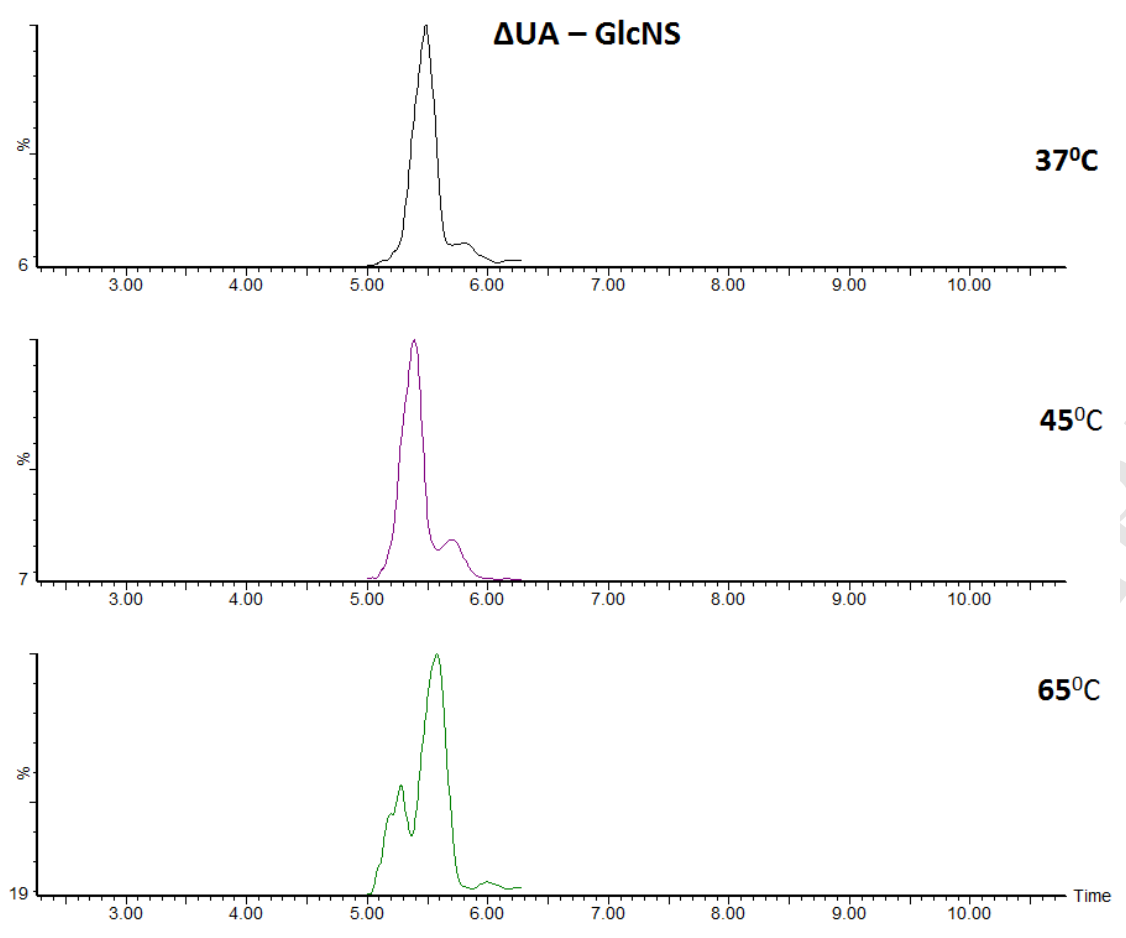

Figure 1d: SIR chromatogram of $\triangle \mathrm{UA}-$ GIcNS when derivatized at different temperatures. Top: $37^{\circ} \mathrm{C}$, middle: $45^{\circ} \mathrm{C}$, and bottom: $65^{\circ} \mathrm{C}$.

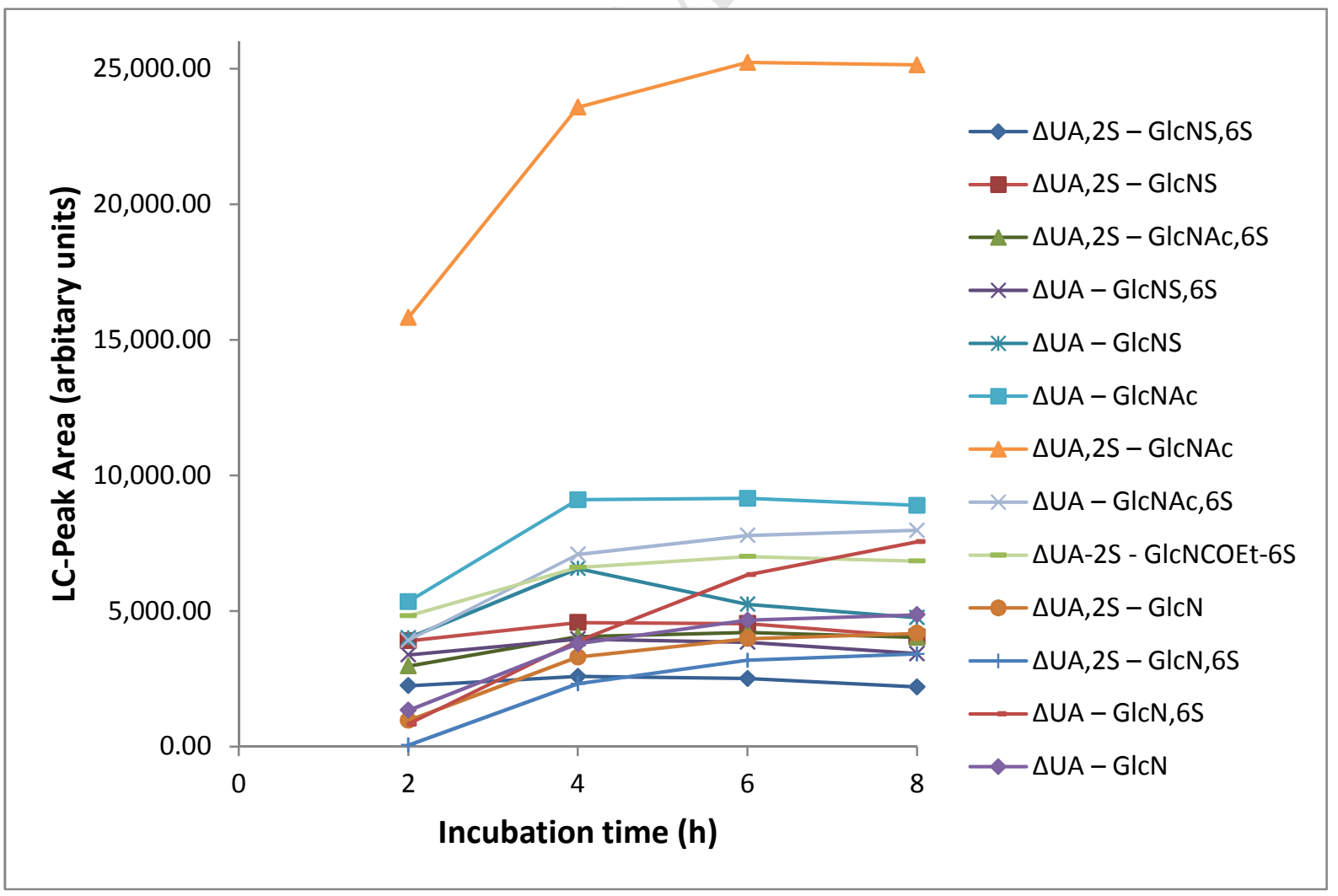

Figure 1e: LC-peak area against derivatization incubation time of AMAC-derivatized heparin/HS DS standard. Heparin/HS DS concentration: $2.5 \mu \mathrm{g} / \mathrm{mL}$. 


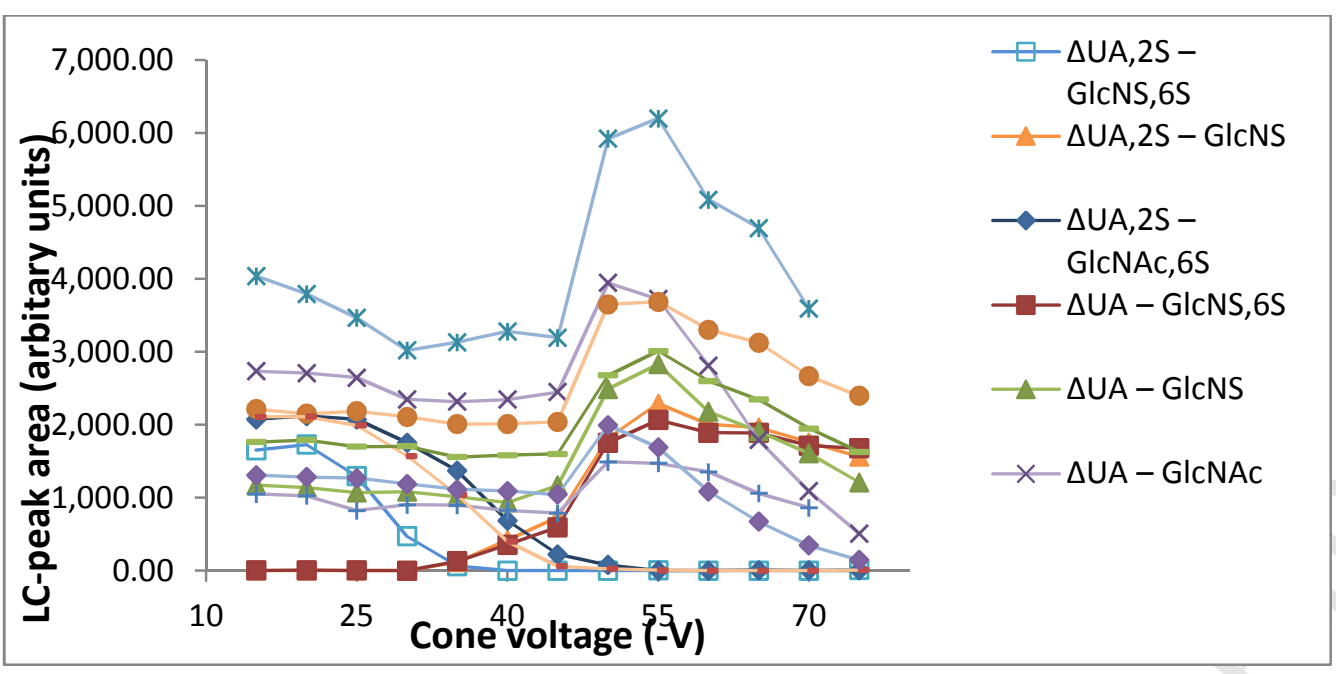

Figure 2a: LC-peak area of AMAC derivatized heparin/HS DS standard (1 $\mu \mathrm{g} / \mathrm{mL})$ as a function of cone voltage.

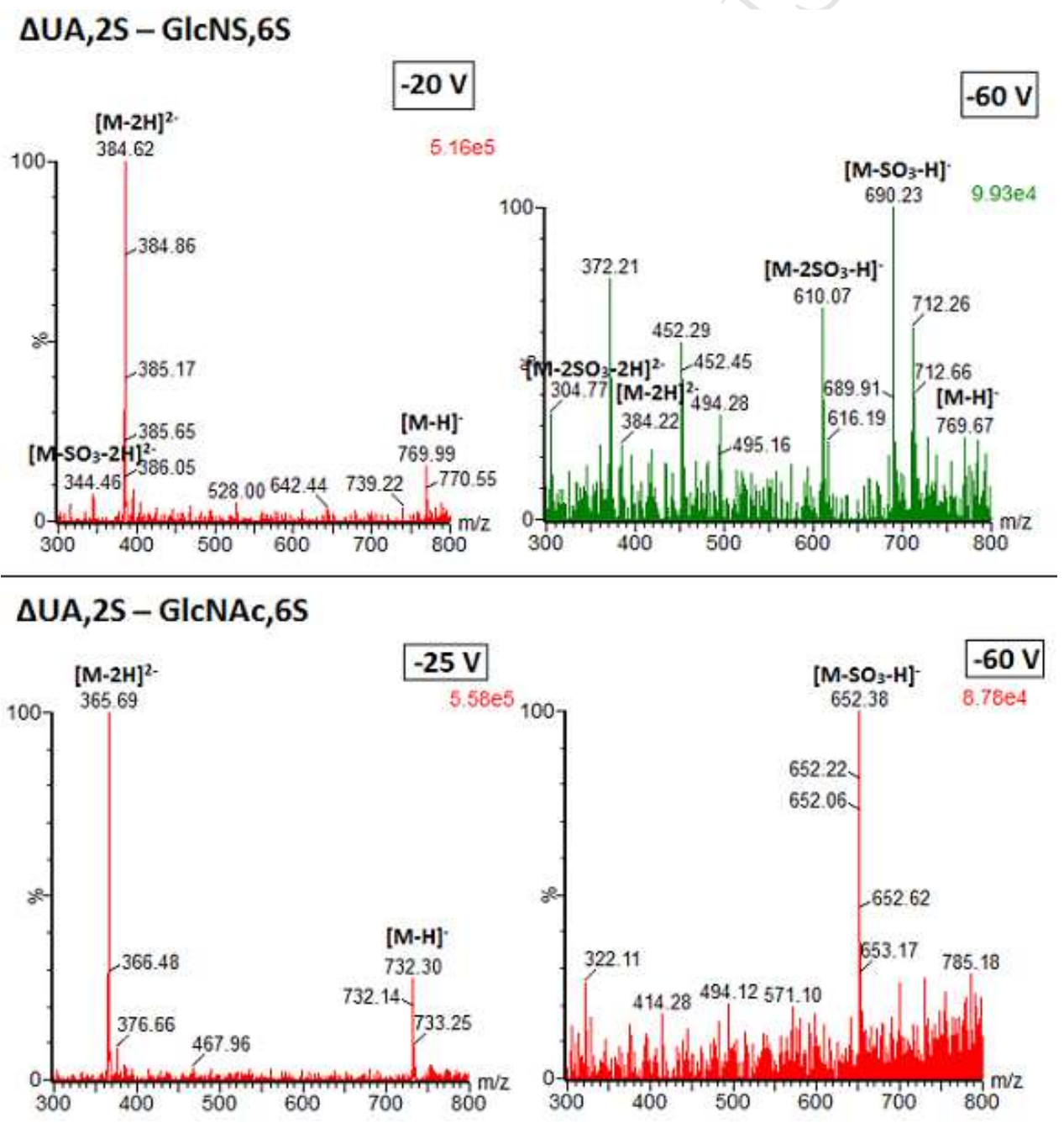

Figure 2b: Mass spectrum of $100 \mu \mathrm{g} / \mathrm{mL}$ AMAC-derivatized $\triangle \mathrm{UA}, 2 \mathrm{~S}$ - GlcNS,6S (Top) obtained at a cone voltage of -20 and $-60 \mathrm{~V}$ and $\triangle U A, 2 S-$ GlcNAc,6S (bottom) obtained at 25 and $-60 \mathrm{~V}$ 


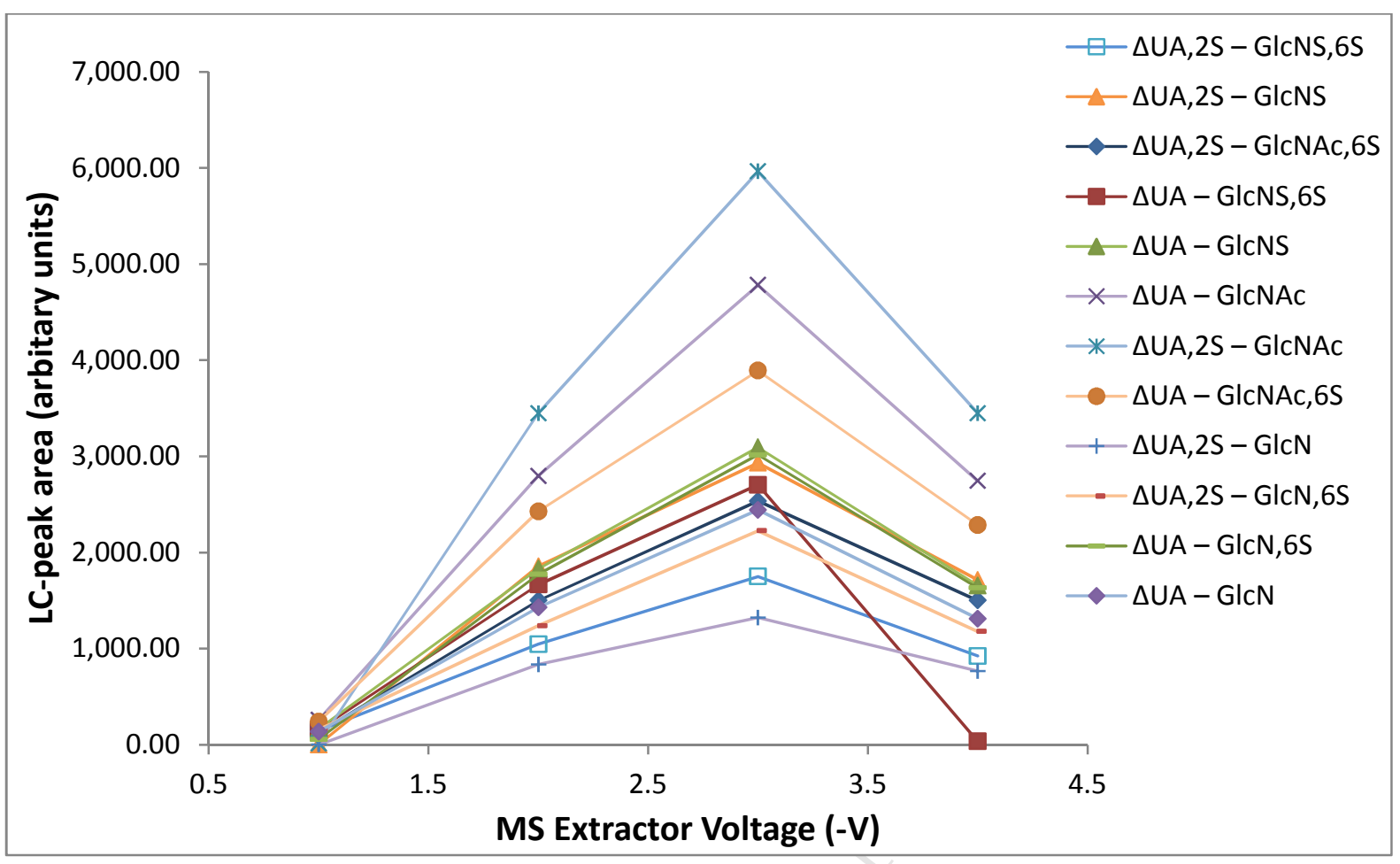

Figure 2c: LC-peak area against MS extractor voltage of AMAC-derivatized heparin/HS DS. Concentration: $1 \mu \mathrm{g} / \mathrm{mL}$.

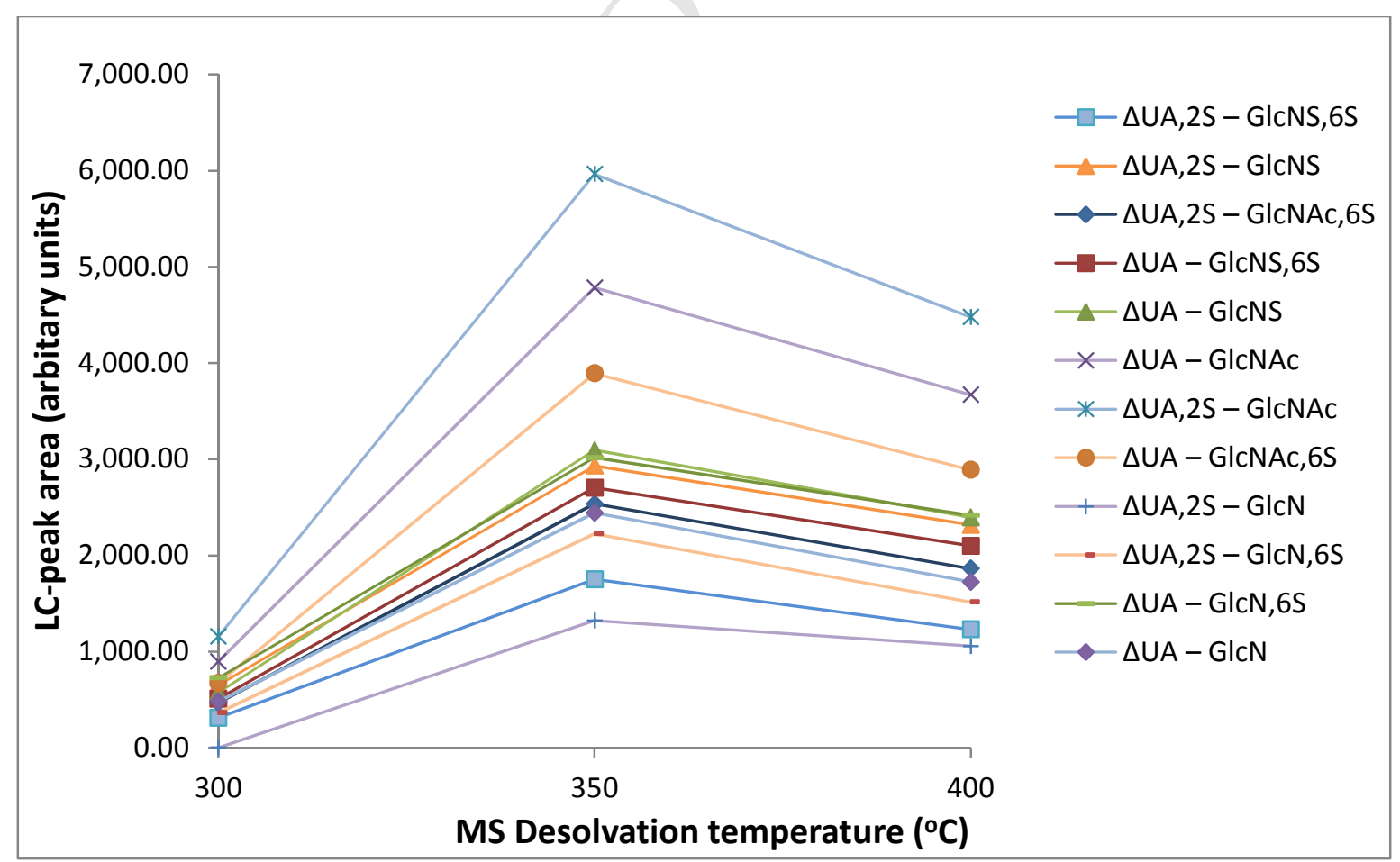

Figure 2d: LC-peak area as a function of desolvation temperature of AMAC-derivatized heparin/HS DS. Concentration: $1 \mu \mathrm{g} / \mathrm{mL}$. 


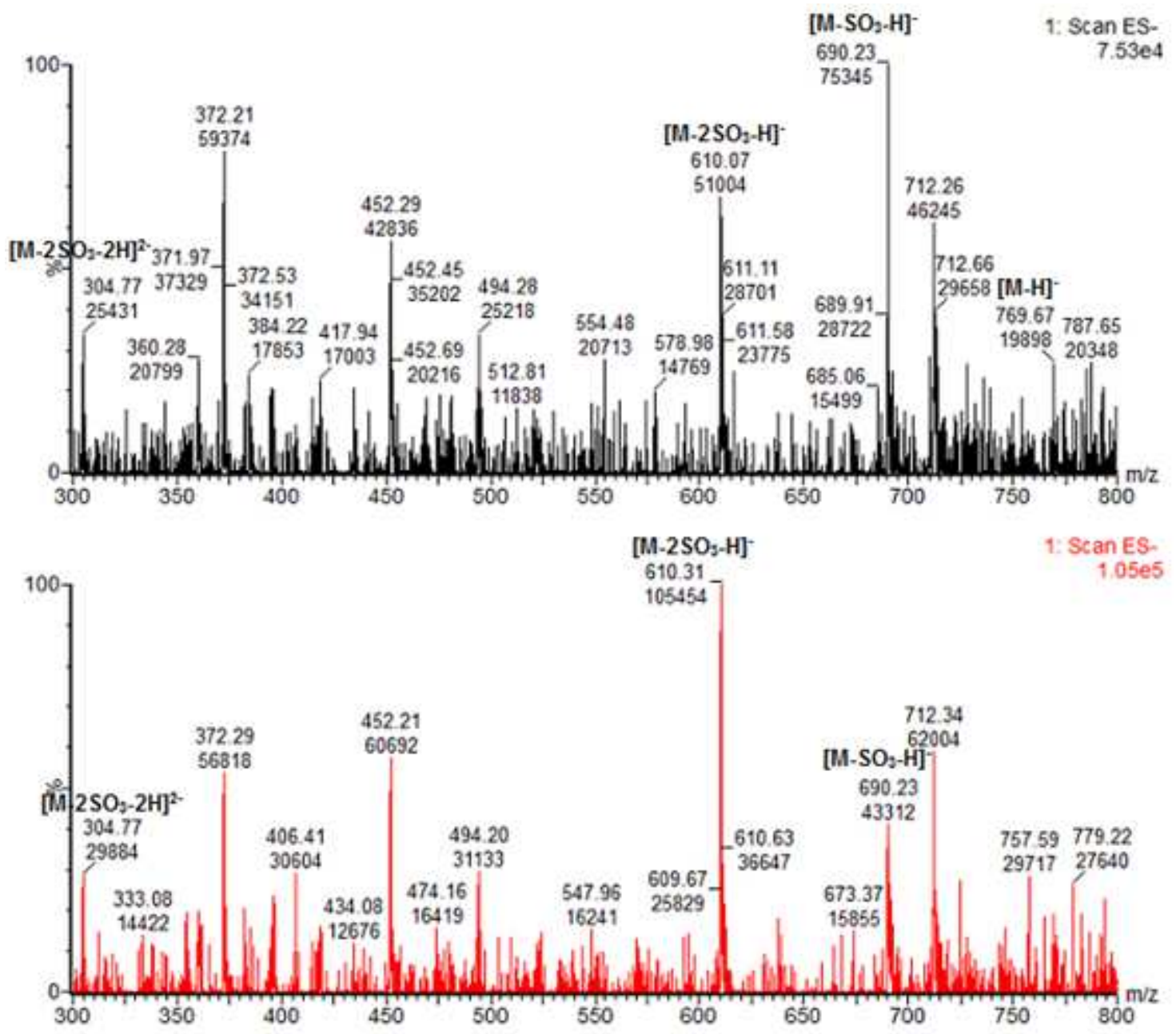

Figure 2e: Mass spectrum of AMAC-derivatized $\triangle U A, 2 S$ - GlcNS,6S obtained at a cone voltage of $-60 \mathrm{~V}$ and desolvation temperature of $350{ }^{\circ} \mathrm{C}$ (top) and $400{ }^{\circ} \mathrm{C}$ (bottom). Top number: $m / z$, bottom number: intensity 

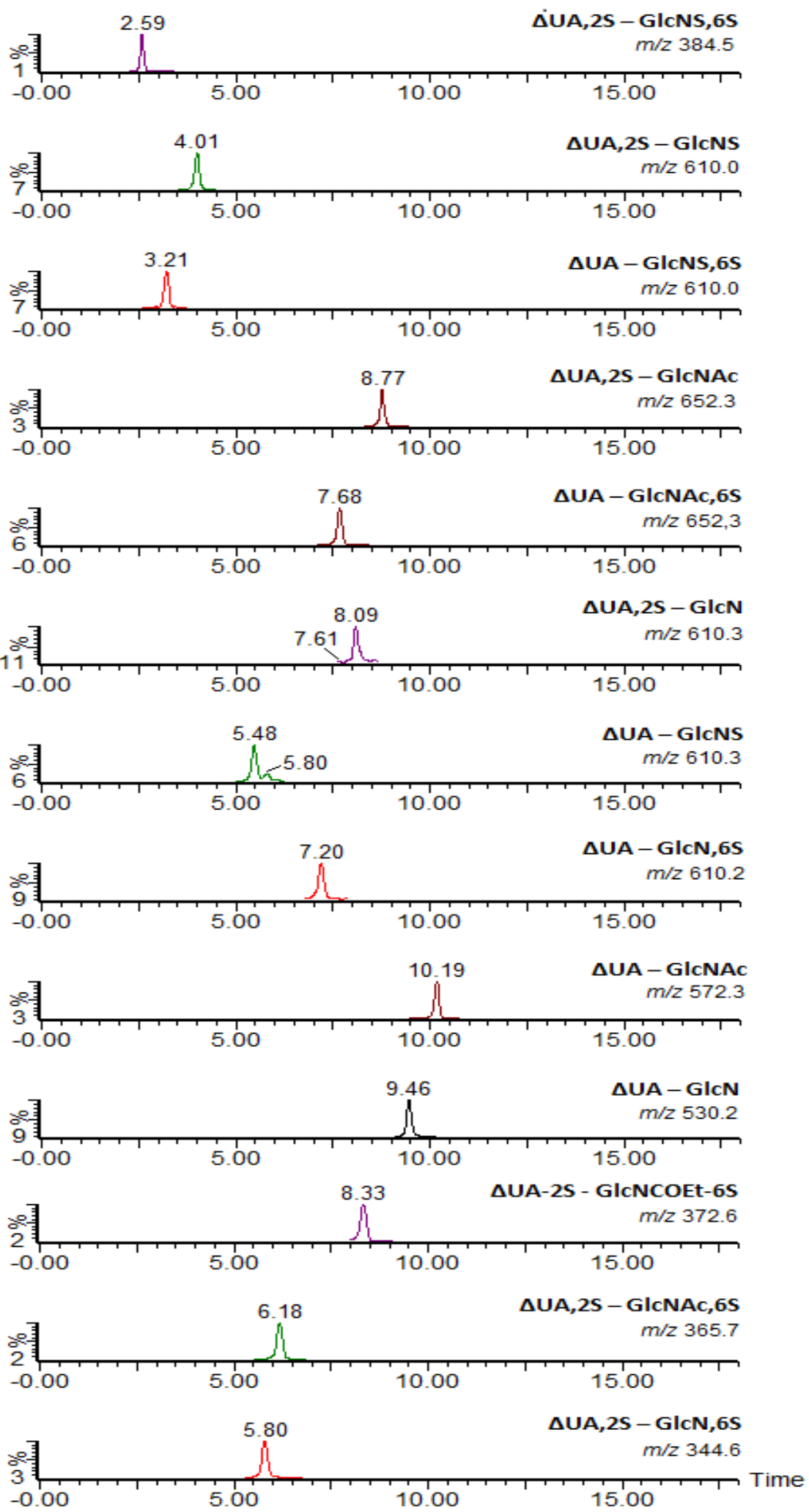

Figure 3: The SIR chromatograms of AMAC-derivatized heparin/HS DS using optimal derivatization and MS conditions. $10 \mu \mathrm{g} / \mathrm{mL}$, injection volume: $5 \mu \mathrm{L}$ 


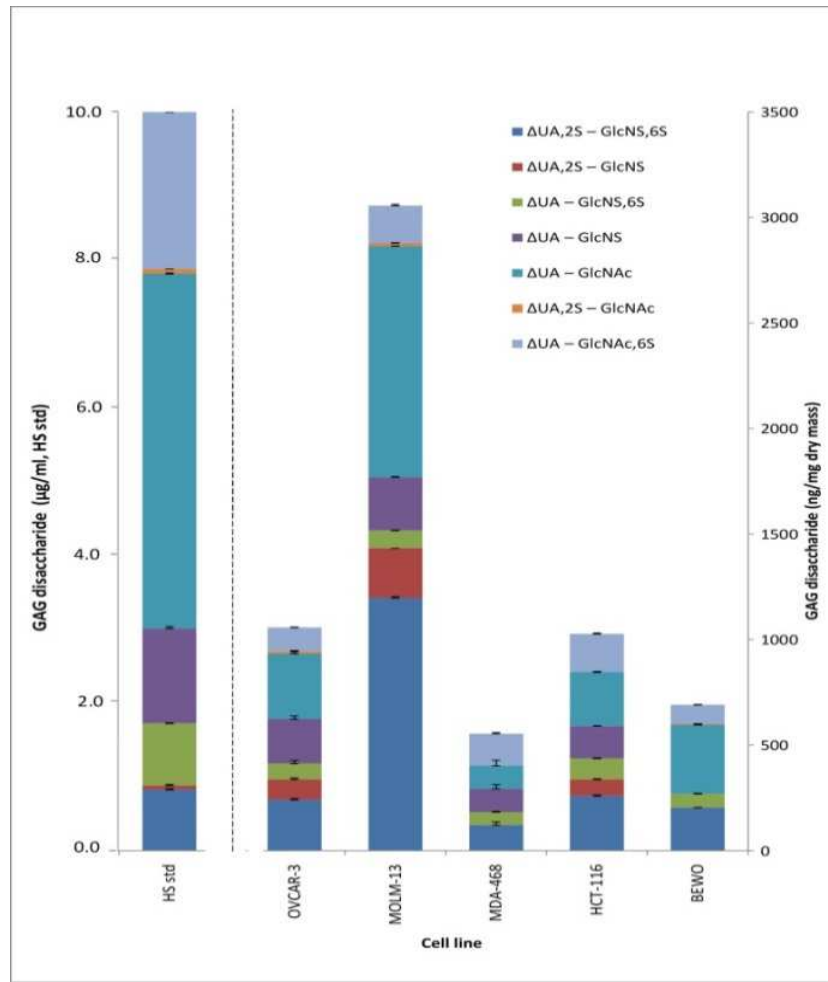

Figure 4: Bar chart and table showing the concentrations of recovered heparin/HS DS composition of heparan sulphate standard $(\mu \mathrm{g} / \mathrm{ml})$ and different cell lines $(\mathrm{ng} / \mathrm{mg}$ dry weight). 